\title{
Article \\ Flowing Material Balance and Rate-Transient Analysis of Horizontal Wells in Under-Saturated Coal Seam Gas Reservoirs: A Case Study from the Qinshui Basin, China
}

\author{
Suyang Zhu ${ }^{1}$ and Alireza Salmachi ${ }^{2, *(1)}$ \\ 1 State Key Laboratory of Oil and Gas Reservoir Geology and Exploitation, Southwest Petroleum University, \\ Chengdu 610500, China; suyang.zhu@swpu.edu.cn \\ 2 Australian School of Petroleum and Energy Resources, University of Adelaide, Adelaide 5005, Australia \\ * Correspondence: alireza.salmachi@adelaide.edu.au
}

check for

updates

Citation: Zhu, S.; Salmachi, A. Flowing Material Balance and Rate-Transient Analysis of Horizontal Wells in Under-Saturated Coal Seam Gas Reservoirs: A Case Study from the Qinshui Basin, China. Energies 2021, 14, 4887. https://doi.org/ $10.3390 /$ en14164887

Academic Editors: Victor Terekhov and Reza Rezaee

Received: 5 July 2021

Accepted: 3 August 2021

Published: 10 August 2021

Publisher's Note: MDPI stays neutral with regard to jurisdictional claims in published maps and institutional affiliations.

Copyright: (c) 2021 by the authors. Licensee MDPI, Basel, Switzerland. This article is an open access article distributed under the terms and conditions of the Creative Commons Attribution (CC BY) license (https:/ / creativecommons.org/licenses/by/ $4.0 /)$.

\begin{abstract}
Two phase flow and horizontal well completion pose additional challenges for rate-transient analysis (RTA) techniques in under-saturated coal seam gas (CSG) reservoirs. To better obtain reservoir parameters, a practical workflow for the two phase RTA technique is presented to extract reservoir information by the analysis of production data of a horizontal well in an under-saturated CSG reservoir. This workflow includes a flowing material balance (FMB) technique and an improved form of two phase (water + gas) RTA. At production stage of a horizontal well in under-saturated CSG reservoirs, a FMB technique was developed to extract original water in-place (OWIP) and horizontal permeability. This FMB technique involves the application of an appropriate productivity equation representing the relative position of the horizontal well in the drainage area. Then, two phase (water + gas) RTA of a horizontal well was also investigated by introducing the concept of the area of influence (AI), which enables the calculation of the water saturation during the transient formation linear flow. Finally, simulation and field examples are presented to validate and demonstrate the application of the proposed techniques. Simulation results indicate that the proposed FMB technique accurately predicts OWIP and coal permeability when an appropriate productivity equation is selected. The field application of the proposed methods is demonstrated by analysis of production data of a horizontal CSG well in the Qinshui Basin, China.
\end{abstract}

Keywords: Two phase flow; rate-transient analysis; flowing material balance; coal seam gas; horizontal well

\section{Introduction}

Hydraulic fracturing and horizontal well completion are effective approaches to stimulate reservoirs, and enhance well productivity in coal seam gas (CSG) reservoirs, respectively [1-3]. An effective tool to estimate reservoir and stimulation information of horizontal wells is the modern production data analysis (PDA), including rate-transient analysis (RTA) and flowing material balance (FMB) techniques. Both techniques are powerful methods for reservoir characterization in unconventional reservoirs, such as tight gas, shale gas, and dry CSG reservoirs, when single-phase flow occurs [1,4-6]. In the production data analysis (single-phase flow), a diagnostic curve is plotted using rate-normalized pressure (RNP) and pseudo-time to identify the flow regimes [1,7-9]. Then, reservoir and stimulation properties, including original gas-in-place (OGIP), permeability, skin factor, and hydraulic fracture characteristics (length and conductivity), can be extracted in each flow regime using specialized straight-line plots. For CSG reservoirs, material balance pseudo-time and superposition time are employed in RTA studies due to the change in the bottom hole pressure and the production rate [1,9]. The gas desorption impact on pressure is also considered in material balance pseudo-time using desorption compressibility, which is included in the total compressibility as an independent term $[10,11]$. 
The RTA of a multi-staged hydraulically fractured horizontal well is complicated and may require additional information, such as a micro-seismic interpretation, to obtain promising results $[1,2,12,13]$. The production history (recorded on a daily basis) of a typical horizontal well may exhibit five flow regimes, namely, early radial, formation linear, elliptical, pseudo-radial, and boundary-dominated flow regimes [1]. In unconventional reservoirs, including tight gas, shale gas, and CSG reservoirs, the horizontal interval of the well should be long enough to enhance well productivity and, hence, rectangular drainage areas are common [14-18]. Early radial, formation linear, and boundary-dominated flow regimes can generally be captured in horizontal wells because the horizontal interval penetrates most part of the drainage area, thereby eliminating elliptical and pseudo-radial flow regimes.

The RTA methods for a horizontal well in dry CSG reservoirs utilize analytical solutions developed for single-phase flow in tight and shale gas reservoirs [2,15,19]. A summary of flow regime analysis for a horizontal well in dry CSG reservoirs is shown in Table $1[1,3,20]$.

Table 1. Summary of flow analysis for a horizontal well in dry CSG reservoirs.

\begin{tabular}{|c|c|c|c|}
\hline Flow Regimes & $\begin{array}{c}\text { Log-Log } \\
\text { Diagnostic }\end{array}$ & Straight Line Plot & Extracted Properties \\
\hline Early radial flow & Zero slope & $R N P_{g}$ vs. $\log t_{c a}$ or $t_{c a, r s p}$ & $\sqrt{k_{y} k_{z}}=\frac{1637 T}{m L_{w}}$ \\
\hline Linear flow & Half slope & $R N P_{g}$ vs. $t_{c a}^{0.5}$ or $t_{c a, l s p}$ & $\sqrt{k_{y}}=\frac{576.56 T f_{c p}^{*}}{m h L_{w} \sqrt{\varphi \mu_{g} c_{t}^{*}}}$, OGIP $=f_{c p}^{*} \frac{200 S_{g i} \sqrt{t_{e h s}}}{m \varphi B_{g i} c_{t}^{*}}$ \\
\hline Boundary-dominated flow & Unit slope & $\frac{1}{R N P_{g}}$ vs. $\frac{G_{i}\left[m\left(p_{i}\right)-m\left(p_{R}\right)\right]}{\left[m\left(p_{i}\right)-m\left(p_{w f}\right)\right]}$ & $G_{i}=-\frac{b}{m}$ \\
\hline
\end{tabular}

In under-saturated CSG reservoirs, the fracture system is generally saturated with water and more than $90 \%$ of gas is in the sorption phase at the initial reservoir conditions [21-25]. Hence, the production generally starts with single-phase (water) flow. Yarmohammadtooski [26] utilized early water production data of a dewatering vertical well in the Fairview Field, eastern Australia, to measure original water-in-place (OWIP) and absolute permeability of the Bandanna Coal Formation using FMB methods. Shahamat and Clarkson (2017) calculated original oil-in-place (OOIP) for a multi-fractured horizontal well using a multi-well, multi-phase flowing material balance method; however, permeability of the reservoir was not calculated.

When production enters the two phase (water + gas) flow stage, the current studies of RTA in under-saturated CSG reservoirs mainly refer to the study of two phase (oil + solution gas) flow or two phase (gas + condensate oil) flow in tight and shale reservoirs [14,18,27]. Previous studies have shown that two phase flow in transient flow regimes presents significant challenges to RTA application in CSG reservoirs, leading to the incorrect identification of flow regimes and inaccurate extraction of reservoir information [8,12,28,29]. Following empirical correction methods in transient linear flow [15], Qanbari and Clarkson [17] proposed an analytical correction factor $\left(f_{c p}^{*}\right)$ for a formation linear flow regime to study two phase (gas + oil) RTA with stress-dependent permeability using an iterative integral approach. This correction factor $\left(f_{c p}^{*}\right)$ can dramatically increase the accuracy. To simplify multi-phase flow RTA in tight reservoirs, Mohan [30] introduced the total equivalent production rate to replace the primary fluid rate for RTA in transient and boundary-dominated flow regimes. To overcome the two phase problem for RTA in CSG reservoirs, Qanbari and Clarkson [14] introduced the concept of contacted water-in-place (CWIP) and the dynamic drainage area (DDA), and proposed a workflow for the analysis of formation linear flow regimes inspired by the method used in tight and shale reservoirs $[17,31]$. For the DDA in undersaturated CSG reservoirs, water production data was employed to calculate the investigation distance in formation linear flow regimes [20]. Because the DDA is calculated using pressure data, the DDA in under-saturated CSG reservoirs include both a two phase (gas + water) flow zone and a single-phase water flow zone. 
The application of the DDA results in underestimation of water saturation in the DDA, which consequently results in gas relative permeability values that are lower than the actual values. In our previous study [32], the concept of the area of influence (AI) was presented to obtain the average water saturation in formation linear flow regimes. It was shown that the application of the AI can result in more accurate estimation of hydraulic fracture half-length in transient linear flow regimes. Nevertheless, the approach in the previous study [32] was developed for the transient linear flow regime of a vertical well stimulated with a single hydraulic fracture.

In this paper, we develop a workflow for two phase RTA to estimate reservoir information extracted from the production profile of a horizontal well. The results from the proposed FMB method (single-phase water flow) allows crosschecking with the results obtained from two phase (water + gas) RTA of existing flow regimes (e.g., formation linear flow and boundary-dominated flow) when the concept of the AI is applied. Simulation and field examples are presented to demonstrate the application of the proposed FMB, the concept of the AI, and the two phase workflow.

\section{Study Area and Wellbore Description}

The commercial production of CSG in China started in the late 1980s, with total OGIP estimated to be 1298.65 Tscf in shallow coalbeds (depth < 6561 ft) [33,34]. The Qinshui Basin is located in the mid-eastern area of China, and covers an area of $23.49 \times 10^{3} \mathrm{~km}^{2}$ (Figure 1). The Qinshui Basin is a NNE (north-north-east) large-scale synclinorium, and the long axis of the Qinshui Basin has a length of approximately $330 \mathrm{~km}$ and a northeast-southwest direction [33,35]. The CSG wells in China have increased significantly from 1183 to 12,547 during the period of 2006 to 2012, and approximately $40 \%$ of these wells were drilled in the Qinshui Basin. By the end of 2014, the CSG demonstration production zone was established in the Qinshui Basin, accounting for 71\% of the total number of producing wells, $65 \%$ of the proven OGIP of CSG, and 81\% of the yearly production in China [36].

The study area is located in the Panzhuang production block, which is one of the main CSG production blocks in the Qinshui Basin [37,38]. The Panzhuang block is located at the southern edge of the Qinshui Basin (Figure 1) and the target coal is seam No.3, which is located in the middle and lower parts of Shanxi Formation [39]. The thickness of coal seam No.3 ranges from $14.59 \mathrm{ft}$ to $28.71 \mathrm{ft}$. In the Panzhuang block, coal seam No.3 is separated from the upper sandstone $\mathrm{K} 8$ by siltstone, carbonaceous mudstone, and mudstone. Coal seam No.3 is the target seam for CSG production in the Qinshui Basin [40] and the present burial depth of coal seam No.3 ranges from $1012 \mathrm{ft}$ to $4593 \mathrm{ft}$. The coal rank is anthracite in the study area, with an average $R_{\text {omax }}$ of $3.78 \%$ [41]. Coal seam No.3 has high adsorption capacity, with Langmuir volume on a DAF (dry-ash free) basis ranging from 938 to 1585 Scf/ton, mostly between 1059 and 1412 Scf/ton, and, on average, 1307 Scf/ton. The gas content of coal seam No.3 in the study area ranges from 282 to $741 \mathrm{Scf} /$ ton [42]. Gas and water production rates vary significantly in each production block of the Qinshui Basin $[35,43]$, with the dewatering stage ranging from only one week to a few months in the Panzhuang production block.

The target well was completed in coal seam No.3 using the horizontal well technique. The wellbore schematic is given in Figure 1. Surface casings (13-3/8 inch) were set at the vertical depth of $459 \mathrm{ft}$ and the intermediate casing (9-5/8 inch) was placed at the vertical depth of $1653 \mathrm{ft}$. The 5-1/2 inch production casing was run in the horizontal section of the wellbore (at the true vertical depth of $1857 \mathrm{ft}$ ). The effective production interval of this horizontal well is approximately $8960 \mathrm{ft}$. 


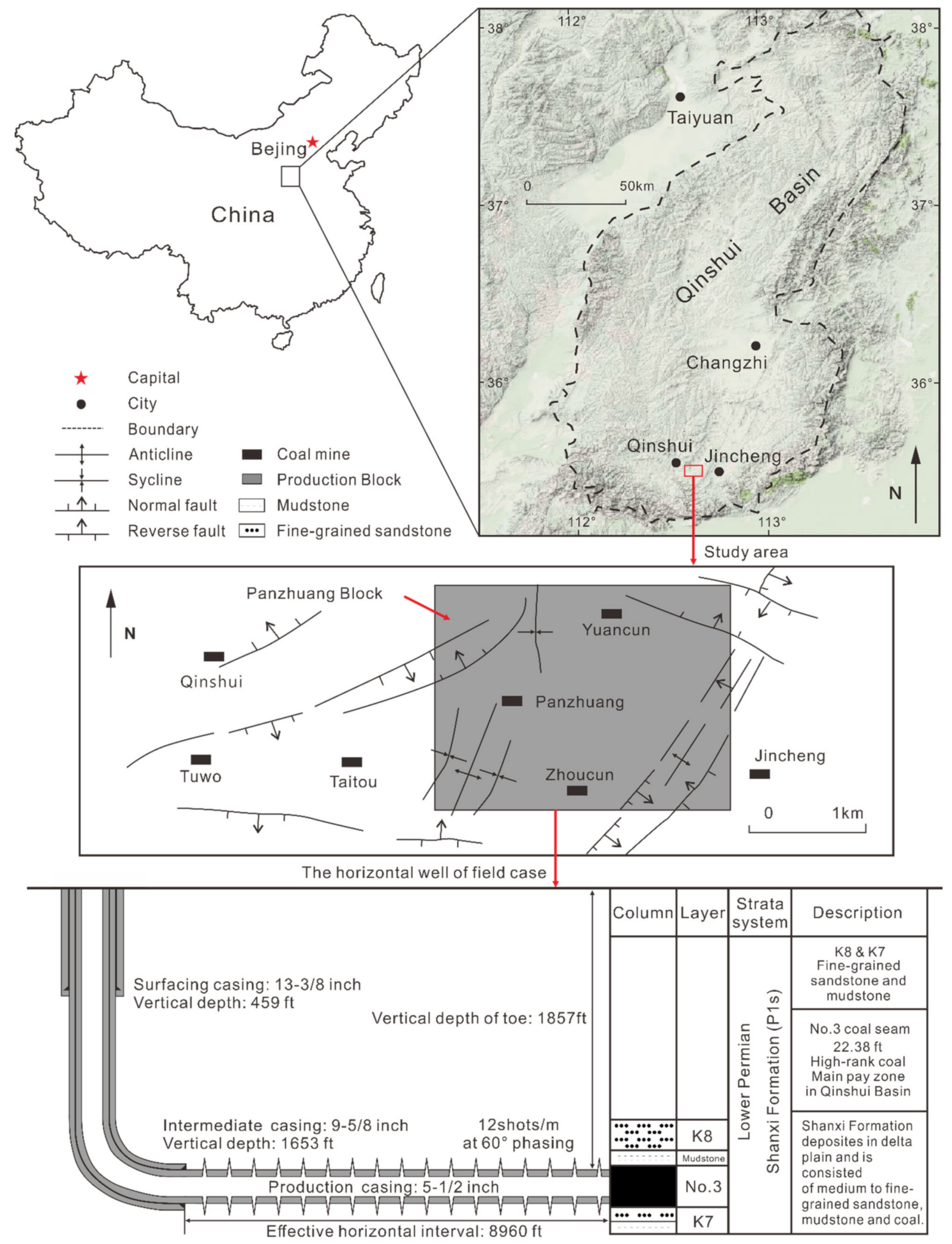

Figure 1. The study area and target horizontal well in the Panzhuang block. 


\section{Methodology}

3.1. Flowing Material Balance for a Horizontal Well in an Undersaturated CSG Reservoir (Single-Phase Water)

In under-saturated CSG reservoirs, during the dewatering process (single-phase flow), boundary effects may easily dominate the flow. In the boundary-dominated flow regime, using the FMB method, the drainage area and absolute permeability of a vertical well can be extracted. To extract the permeability of a horizontal well, an appropriate equation should be employed.

The general FMB equation for single-phase flow (water) is given by Equation (1). In the general form, $b_{p s s}$ accounts for the pressure loss due to the pseudo-steady state inflow of fluid (see Appendix A).

$$
\frac{q_{w}}{\Delta p}=-\frac{W_{p} B_{w}}{\Delta p c_{t}} \frac{1}{N_{w} b_{p s s}}+\frac{1}{b_{p s s}}
$$

When $b_{p s s}$ is obtained using the straight-line form of Equation (1), the permeability of the reservoir can be extracted using $b_{p s s}$. For a stimulated vertical well, the productivity equation with equivalent skin factor can be used in the FMB method [26,32]. However, for a horizontal well, the same productivity equation could lead to errors. In this section, we derive a new form of FMB to analyze the early single-phase water production rates using different productivity equations.

The relative position of the horizontal well in the drainage area may result in the development of an elliptical flow regime followed by a boundary-dominated flow regime. In this case, the productivity of the horizontal well can be estimated using the Joshi equation (see Appendix A) and, hence, $b_{p s s}$ takes the following form:

$$
b_{p s s}=\frac{141.2\left(\mu_{w} B_{w}\right)\left[\ln \frac{a+\sqrt{a^{2}-\left(L_{w} / 2\right)^{2}}}{L_{w} / 2}\right]}{k_{y} h}
$$

where $a$ is the major axis of the elliptical drainage area and can be calculated using the equivalent drainage radius $\left(r_{\mathrm{e}}\right)$ and the length of horizontal interval $\left(L_{w}\right)$, shown as:

$$
a=\left(L_{w} / 2\right)\left[\frac{1}{2}+\sqrt{\frac{1}{4}+\frac{1}{\left(L_{w} / 2 r_{e}\right)^{4}}}\right]^{0.5}
$$

The relative position of the horizontal well in the drainage area can also result in formation linear flow followed by boundary-dominated flow, particularly in long horizontal wells. For example, the relative position of our study well, with respect to the nearby wells in the Qinshui Basin and its long horizontal interval (8960 ft), fits in this category. In this case, the productivity of the horizontal well can be calculated using the Clarkson equation [28]. Then, the expression of $b_{p s s}$ can be written as:

$$
b_{p s s}=\frac{141.2\left(\mu_{w} B_{w}\right)\left(\frac{2 \pi y_{d}}{L_{w}}\right)}{k_{y} h}
$$

The detailed derivation of the FMB equations using both Joshi and Clarkson's productivity equations are shown in Appendix A. Simulation examples are employed below to demonstrate how coal permeability is obtained using the proposed FMB equations.

\subsection{Water Saturation Calculation in the Area of Influence (AI)}

When dewatering reduces the reservoir pressure to a critical value, the gas begins to desorb and flows in the cleats and fractures of the coal. This pressure value is named the critical desorption pressure, which is an important value to separate the boundary 
between single-phase water flow and two phase flow in coal. After the single-phase (water) production stage, the two phase (water + gas) production begins for a horizontal well in an under-saturated CSG reservoir.

For two phase RTA, water saturation is the key factor to extract reservoir information. To calculate the correct water saturation, which is used to determine gas relative permeability for correcting the RNP, the area of influence (AI) is introduced as the area where gas desorption and flow occurs. Unlike the dynamics drainage area (DDA) [20,44], the AI in an under-saturated CSG reservoir is the actual area of the two phase flow zone. Hence, in transient flow regimes, the AI in an under-saturated CSG reservoir is smaller than the DDA and, as a result, average water saturation in the AI provides more accurate results for the purpose of two phase RTA. In our previous study [32], we showed that the application of the AI in the analysis of formation linear flow of a hydraulically fractured CSG well (vertical) resulted in a more accurate estimation of the fracture half-length compared to the DDA.

In this paper, we introduce the AI for both early radial flow and formation linear flow regimes for a horizontal well in an under-saturated CSG reservoir. Because the early radial flow regime occurs quickly, the impacts of pressure on rock and fluid properties may be ignored. The average water saturation in the AI of early radial flow regime can be approximately obtained using the water saturation in the cylinder around the horizontal interval (Equation (5)), where $L_{w}$ is the length of the horizontal interval and the half thickness of the coal seam $(h / 2)$ is the radius of the cylinder. With the average water saturation in $\mathrm{AI}$ of early radial flow, the geometric-average permeability can be estimated using two phase RTA methods (Appendix B).

$$
s_{w}=\frac{B_{w}\left(W_{p}-W_{e}\right)}{1939.5 \pi L_{w} h^{2} \varphi_{i}}
$$

In a transient formation linear flow regime, the average water saturation in the AI is calculated using gas production data to represent the two phase flow in the area of influence. Figure 2 shows the pressure distribution of formation linear flow for a horizontal well in a coal seam. The critical desorption pressure separates the single water flow and the two phase flow in the coal. The area of influence and the dynamic drainage area are shown separately in Figure 2 as the formation linear flow propagates. Because the AI is smaller than the DDA, the average water saturation in the DDA may be overestimated.

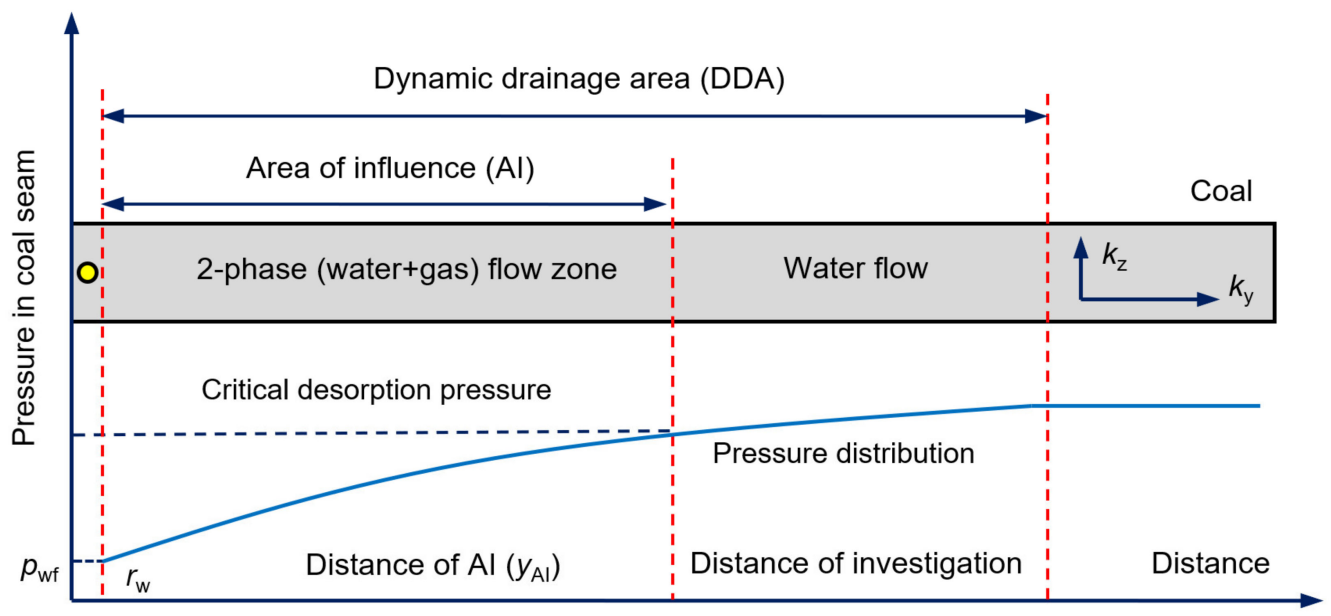

Figure 2. The AI and DDA of the transient formation linear flow regime of a horizontal well in an under-saturated CSG reservoir.

Inspired by the calculation of the DDA [44], an iterative process for average pressure and average water saturation in the $\mathrm{AI}$ of a transient formation linear flow regime is pro- 
posed for under-saturated CSG reservoirs. This iterative process combines the calculation of the AI and the material balance method. The detailed iterative process can be seen in our previous study [32]. The calculation of average pressure and average water saturation in transient linear flow regimes requires simultaneously solving four equations. For the transient linear flow regime, the gas production rate of a horizontal well [44] can be expressed as:

$$
q_{g}=\frac{k_{y} h \bar{k}_{r g}\left[m\left(\bar{p}_{A I}\right)-m\left(p_{w f}\right)\right]}{1424 T\left[\frac{4}{\pi}\left(\frac{y_{\mathrm{AI}}}{L_{w}}\right)\right]}
$$

where $y_{\mathrm{AI}}$ is the distance of the $\mathrm{AI}$ in the transient linear flow regime (Qanbari and Clarkson 2013a), which can be expressed by:

$$
y_{\mathrm{AI}}=\delta \sqrt{\frac{k_{y} t}{\left(\varphi \mu_{g} c_{t}^{*}\right)_{i}}}
$$

Under the constant bottom-hole flowing pressure condition, $\delta=0.159$. This coefficient depends on the operational conditions (rate and flowing bottom-hole pressure). In this work, $\delta=0.159$ is used for all examples and practice has indicated that the extracted results are not highly sensitive to this coefficient [14,20,44,45].

For formation linear flow, the material balance equation is derived to calculate the average water saturation and pressure in the area of influence. In the AI of an undersaturated CSG reservoir, gas desorbs, leading to gas production. Hence, the cumulative gas production $\left(G_{p}\right)$ is equal to the decline in the gas content in the AI of formation linear flow, which propagates with time. The decrease in gas content can be expressed by the change in gas saturation and sorption capacity. The expanding AI is a function of the length of the horizontal interval $\left(L_{w}\right)$ and the distance of the AI ( $\left.y_{\mathrm{AI}}\right)$. Therefore, a form of material balance equation can be developed in this scenario, as given by (Equation (8)):

$$
G_{p}=2 L_{w} y_{A I} h\left[\left(\frac{V_{L} p_{c d}}{p_{L}+p_{c d}}\right)-\left(\left.\frac{\varphi S_{g}}{B_{g}}\right|_{\bar{p}_{A I}}+\frac{V_{L} \bar{p}_{A I}}{p_{L}+b \bar{p}_{A I}}\right)\right]
$$

To obtain the average pressure in the area of influence, the average water saturation in the AI of transient formation linear flow is required, which can be expressed by:

$$
s_{w}=1-\frac{B_{w}\left(W_{p}-W_{e}\right)}{7758.4 y_{\mathrm{AI}} L_{w} h \varphi_{i}}
$$

The simultaneous solutions for Equations (6)-(9) require the iterative method, which is accomplished by trial and error. The details of this iterative method are given in the workflow and can be seen in our previous study [32]. After obtaining the average pressure and average water saturation in the AI of the transient formation linear flow regime, the single-phase RNP is corrected using relative permeability values, and the coal permeability can be extracted using the slope of $k_{\mathrm{rg}} \times R N P_{\mathrm{g}}$ versus $t_{\mathrm{ca}}{ }^{0.5}$ (or superposition time $t_{\mathrm{ca}, \mathrm{lsp}}$ ).

When the transient formation linear flow ends and the boundary effects start to dominate the flow, the OGIP can also be extracted using the formation linear flow regime. Once the end of formation linear flow $\left(t_{\text {ehs }}\right)$ is observed, the distance of the AI ( $\left.y_{\mathrm{AI}}\right)$ can be used to calculate the drainage area of the horizontal well. Then, OGIP can be obtained using the drainage area and gas content of the coal using Equation (10):

$$
\text { OGIP }=2 L_{w} y_{\mathrm{AI}} h \times V_{\text {coal }}=2 \delta h L_{w} V_{\text {coal }} \sqrt{\frac{k_{y} t_{e h s}}{\left(\varphi \mu_{g} c_{t}^{*}\right)_{i}}}
$$


Appendix B summarizes the equations and the procedure to perform two phase RTA for a horizontal well, which were previously developed by other authors $[1,6,32]$ when boundary-dominated flow is observed.

\subsection{Workflow for Two phase RTA in Horizontal Well}

To show two phase RTA for a horizontal well in under-saturated CSG reservoirs, a practical workflow is presented to combine both FMB for the dewatering stage and RTA for two phase flow. The combination allows rigorous crosschecks to be undertaken and can precisely extract reservoir properties. Figure 3 illustrates the sequential procedures in the workflow to extract reservoir information using both single-phase (water) FMB and two phase RTA for the simulation and field examples presented in this work. The early water production is analyzed using the proposed FMB method. The average water saturation in the AI, calculated using our proposed method, is applied to correct the RNP for two phase RTA. The workflow follows the following steps:

(1) The gas rates, water rates, bottom-hole pressure, well completion type, and core analysis should be subsequently collected for the analysis. In addition, other necessary information includes the possible drainage area from the location of wells, gas content, isothermal sorption curve, porosity of cleat, and coal absolute permeability and relative permeability from laboratory tests. A data quality check is necessary, and $\mathrm{RNP}$ and $t_{\mathrm{ca}}$ are then calculated using gas production rates and flowing bottom-hole pressures.

(2) The proposed FMB method is used to first identify the boundary-dominated flow regime and, second, to extract the OWIP and horizontal permeability using the early single-phase water production rates. Note that OWIP, obtained in this step, and the water production history, can be utilized to determine average water saturation for two phase RTA.

(3) Average water saturation is used to correct RNP to construct a diagnostic plot to distinguish available flow regimes, such as early radial flow, formation linear flow, and boundary-dominated flow regimes. Note that, when RNP* is corrected using average water saturation, and calculated using the whole drainage area rather than the area of influence, the slopes of early radial flow and boundary-dominated flow regimes in the diagnostic plot are not exactly equal to 0 and 1, respectively. However, it is possible to identify the early radial flow and boundary-dominated flow regimes due to their distinguishing slopes. This will be demonstrated using simulation examples in next section.

(4) For early radial flow regime, the average water saturation in the AI can be approximated using Equation (5) and the geometric-average permeability is calculated using the slope of $k_{\mathrm{rg}} \times \mathrm{RNP}_{\mathrm{g}}$ versus $\log t_{\mathrm{ca}}$ (or superposition time $t_{\mathrm{ca}, \mathrm{rsp}}$, see Appendix B).

(5) For transient formation linear flow, a value for horizontal permeability $\left(k_{y}\right)$ is initially assumed and the dynamic distance of the $\mathrm{AI}$ is calculated using Equation (7). Then, an initial value for the average pressure in the $\mathrm{AI}\left(\bar{p}_{A I}\right)$ is estimated using Equation (6). Based on the initial value of $\bar{p}_{A I}$, the average water saturation and average pressure in the AI are calculated using the trial-and-error method of the material balance equation (Equations (8) and (9)). Finally, the average pressure and average water saturation are utilized to construct the straight-line plot. The square root of horizontal permeability $\left(\sqrt{k_{y}}\right)$ can be extracted using the slope of $k_{\mathrm{rg}} \times \mathrm{RNP}_{\mathrm{g}}$ versus $t_{\mathrm{ca}}{ }^{0.5}$. The calculated $k_{y}$ is compared with the assumed permeability. This process continues until the calculated value converges. Once the calculation converges and $k_{y}$ is obtained, the vertical permeability $\left(k_{z}\right)$ may be calculated using the geometric-average permeability $\left(\sqrt{k_{y} k_{z}}\right)$, obtained from the early radial flow regime. When the transient formation linear flow regime ends, the end time of linear flow $\left(t_{\text {ehs }}\right)$ can be approximated from the plot of RNP* versus $t_{\mathrm{ca}}{ }^{0.5}$. This end time assists in the estimatation of the total drainage area, which can be used to estimate OGIP when coal gas content is known (see (Equation (10)). The horizontal permeability extracted from formation linear 
flow should be in agreement with the value from the single-phase FMB method. This provides a valuable option for crosschecking.

(6) For the boundary-dominated flow regime, the material balance equations are well developed (see Appendix B), and can be applied to calculate the average reservoir pressure and water saturation. The OGIP can be obtained using the relationship and equations listed in Table 1, and the results should be consistent with the results calculated using other flow regimes (e.g., formation linear flow and early radial flow regimes).

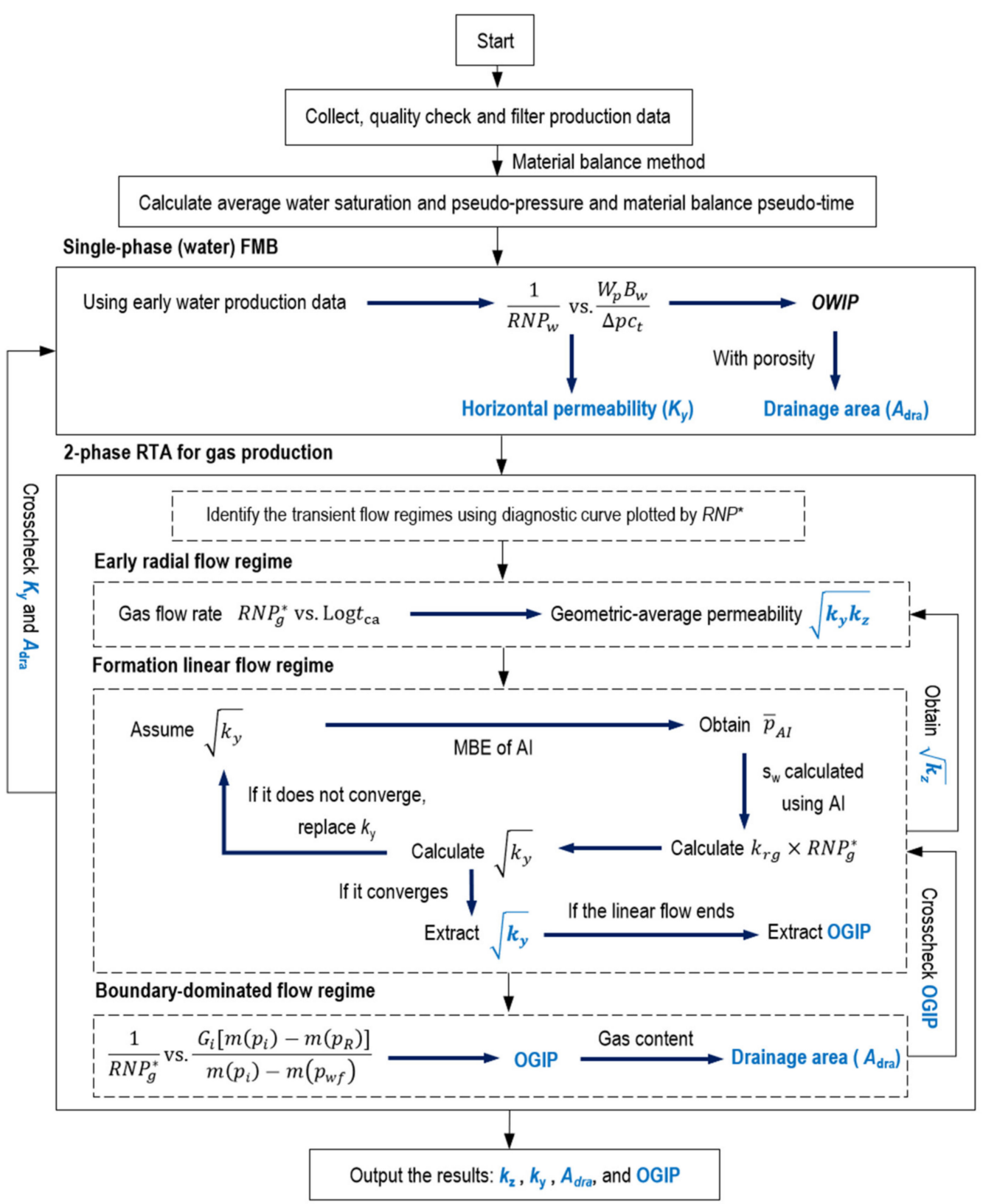

Figure 3. Generalized workflow for two phase RTA of a horizontal well in an under-saturated CSG reservoir.

\section{Results and Analysis}

Both simulation and field examples are presented to validate the proposed singlephase (water) FMB and the application of the AI in the two phase (water + gas) RTA technique for horizontal wells in under-saturated CSG reservoirs. In the simulation ex- 
amples, the single-phase (water) FMB is applied to verify the appropriate productivity equations in Section 3.1 and the two phase RTA study is conducted to test the workflow in Section 3.3. The field example is studied using the proposed workflow to extract coal permeability. The details of simulation and field examples are provided as follows:

Simulation example for single-phase (water) flow:

- $\quad$ Permeability $\left(k_{\mathrm{x}}=k_{\mathrm{y}}=2 \mathrm{mD}, k_{\mathrm{z}}=1 \mathrm{mD}\right)$ and $s_{\mathrm{w}}=100.0 \%$;

- Horizontal well with no hydraulic fractures; Simulation example for two phase (water + gas) flow in under-saturated coal seam:

- Permeability $\left(k_{\mathrm{x}}=k_{\mathrm{y}}=2 \mathrm{mD}, k_{\mathrm{z}}=1 \mathrm{mD}\right)$ and $s_{\mathrm{w}}=100.0 \%$;

- Horizontal well with no hydraulic fractures;

- The length of the horizontal interval is $8400 \mathrm{ft}$ and almost penetrates the whole drainage area. Field example for two phase flow in the Qinshui Basin, China:

- Coal with $100 \%$ initial water saturation, average permeability $2.47 \mathrm{mD}$, and 2.5 years production history;

- Horizontal well with no hydraulic fractures;

- Horizontal interval is $8960 \mathrm{ft}$ and almost penetrates the entire drainage area.

\subsection{Simulation Example}

The gas and water production profile of simulation examples were generated using CBM-module in the ECLIPSE 2011. The model assumptions include:

(1) Dual porosity model;

(2) Gas desorption is described by the Langmuir isotherm and gas diffusion follows Fick's law;

(3) Two phase flow in the coal fracture is modelled using the Darcy law;

(4) Isothermal condition;

(5) Methane is the only component in the model;

(6) The pressure difference in the horizontal interval can be ignored and bottom-hole pressure along the horizontal interval is the same.

Figure 4 shows the five simulation models for a horizontal well located in the drainage area for the simulation of single-phase (water) flow. Note that the relative position of the horizontal well in the drainage area results in the formation of different flow regimes in each model. The well and reservoir properties are listed in Table 2. Most of the reservoir parameters are based on the data from the Panzhuang production block in the Qinshui Basin, China.

In models 1 to 3 , the horizontal interval almost penetrates the entire drainage area, resulting in the formation linear flow regime followed by the boundary-dominated flow regime. In models 4 and 5, elliptical and pseudo-radial flow regimes are formed and followed by the boundary-dominated flow regime. This difference results in using different productivity equations. To test the permeability extracted using Joshi and Clarkson equations, models 1 to 5 are employed to test the proposed single-phase (water) FMB equations for the horizontal well. Model 2 is used to study the two phase (water + gas) RTA method because the horizontal length and drainage area are close to those of our field case.

To generate the production history, the production constraints are set as an initial surface water production rate of $44 \mathrm{Stb} / \mathrm{d}$ and a minimum bottom-hole pressure of $50 \mathrm{psi}$, which are similar to the conditions in the field example. The relative permeability curves and sorption isotherm for simulation purposes are given in Figure 5.

The isothermal sorption data comes from the laboratory test from coal seam No.3 in the Qinshui Basin. 


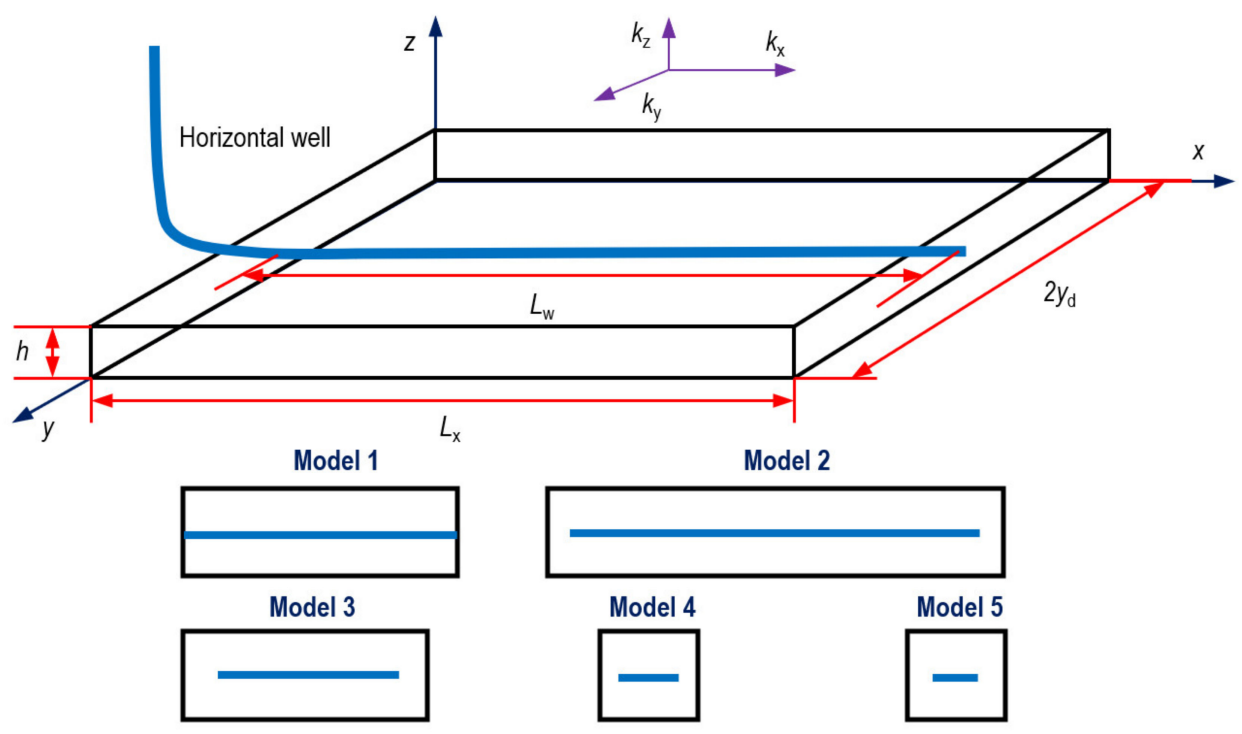

Figure 4. The schematic of a horizontal well located in the drainage area. Note that the relative position of the horizontal well in the drainage area is different in each model.

Table 2. Reservoir properties for the horizontal well in simulation examples.

\begin{tabular}{|c|c|c|c|}
\hline \multirow{2}{*}{ Model } & \multicolumn{3}{|c|}{ Shape Parameters } \\
\hline & $L_{\mathrm{x}}, \mathrm{ft}$ & $y_{\mathrm{d}}, \mathrm{ft}$ & $L_{w}, \mathrm{ft}$ \\
\hline Model 1 & 5740 & 923 & 5740 \\
\hline Model 2 & 8800 & 923 & 8400 \\
\hline Model 3 & 4920 & 923 & 3936 \\
\hline Model 4 & 1968 & 923 & 1312 \\
\hline Model 5 & 1968 & 923 & 984 \\
\hline \multicolumn{3}{|c|}{ Formation parameters } & Value \\
\hline \multicolumn{3}{|c|}{ Thickness of coal, $\mathrm{ft}$} & 22.38 \\
\hline \multicolumn{3}{|c|}{ Cleat porosity, $\%$} & 1.00 \\
\hline \multicolumn{3}{|c|}{ Horizontal permeability of coal, mD } & 2.00 \\
\hline \multicolumn{3}{|c|}{ Vertical cleat permeability of coal, $\mathrm{mD}$} & 1.00 \\
\hline \multicolumn{3}{|c|}{ Coal density, $\mathrm{g} / \mathrm{cm}^{3}$} & 1.50 \\
\hline \multicolumn{3}{|c|}{ Gas content, Scf/ton } & 431.84 \\
\hline \multicolumn{3}{|c|}{ Initial pressure, psi } & 580.16 \\
\hline \multicolumn{3}{|c|}{ Temperature, ${ }^{\circ} \mathrm{F}$} & 94 \\
\hline \multicolumn{3}{|c|}{ Langmuir pressure, psi } & 335.1 \\
\hline \multicolumn{3}{|c|}{ Langmuir volume, Scf/ton } & 1322.751 \\
\hline \multicolumn{3}{|c|}{ Cleat compressibility, $\mathrm{Psi}^{-1}$} & 0.0001 \\
\hline \multicolumn{3}{|c|}{ Water compressibility, $\mathrm{Psi}^{-1}$} & $3.2 \times 10^{-6}$ \\
\hline \multicolumn{3}{|c|}{ Initial gas viscosity, $\mathrm{cp}$} & 0.0153 \\
\hline \multicolumn{3}{|c|}{ Well radius, $\mathrm{ft}$} & 0.1968 \\
\hline
\end{tabular}

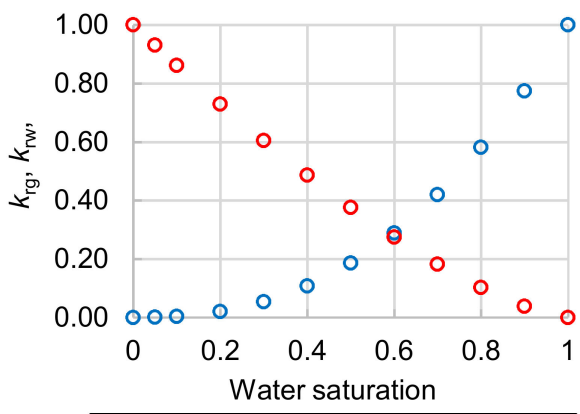

(a)

oWater oGas

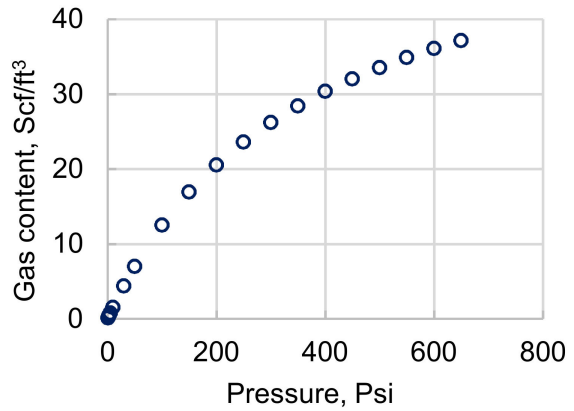

(b)

Figure 5. Parameters of (a) relative permeability curves and (b) Langmuir isotherm in simulation example. 


\subsubsection{Single-Phase (Water) FMB for the Horizontal Well}

To test the single-phase (water) FMB of a horizontal well, models 1 to 5 are used to generate the water production history. In model 1, the linear flow dominates the flow in the horizontal direction. Due to the relative position of the horizontal interval with respect to the drainage area, the formation linear flow regime becomes less apparent from model 1 to model 5. Equations (2) and (4) are utilized to extract the horizontal permeability. The permeabilities extracted for models 1 to 5 are shown in Table 3.

Table 3. Extracted permeability of the simulation example using single-phase (water) FMB.

\begin{tabular}{cccccc}
\hline Calculated Value & Model 1 & Model 2 & Model 3 & Model 4 & Model 5 \\
\hline Using Joshi equation & $k_{\mathrm{y}}=1.01$ & $k_{\mathrm{y}}=1.91$ & $k_{\mathrm{y}}=2.02$ & $k_{\mathrm{y}}=1.48$ & $k_{\mathrm{y}}=0.93$ \\
Using Clarkson equation & $k_{\mathrm{y}}=2.03$ & $k_{\mathrm{y}}=2.13$ & $k_{\mathrm{y}}=2.17$ & $k_{\mathrm{y}}=2.52$ & $k_{\mathrm{y}}=3.22$ \\
\hline
\end{tabular}

As shown in Table 3, when the Clarkson productivity equation is utilized in the proposed FMB method, it provides an accurate estimation of horizontal permeability in model 1. This is because the Clarkson productivity equation was developed for a rectangular drainage area, which is close to that of model 1. In addition, for model 1, the boundary-dominated flow directly follows the formation linear flow. Hence, the productivity equation based on linear flow (Clarkson equation) can extract the permeability with a small error.

The Joshi equation, which was developed for a horizontal well in an elliptical drainage area, provides accurate estimations of horizontal permeability in models 2 and 3 . This is because the elliptical flow exists in models 2 and 3 . For models 4 and 5, the pseudo-radial flow occurs prior to the boundary-dominated flow rather than the elliptical regime. This also leads to large errors in the extracted permeability from the Joshi equation in models 1 , 4 , and 5 .

When the Clarkson productivity equation is utilized in the proposed FMB methods, the accuracy of estimation decreases from model 1 to model 5. Our proposed FMB method well predicts horizontal permeability in models 2 and 3 using both Joshi and Clarkson productivity equations.

\subsubsection{Two phase (Water + Gas) RTA for the Horizontal Well in an Under-Saturated Coal} Seam Gas Reservoir

Figure 6 shows the gas and water production rate for the simulation example (model 2). To perform two phase RTA, flow regimes should be first identified, and the average water saturation values in the AI can then be calculated using the proposed method. The average water saturation, which represents water saturation in the area of influence, is employed to modify the RNP using the gas relative permeability values.

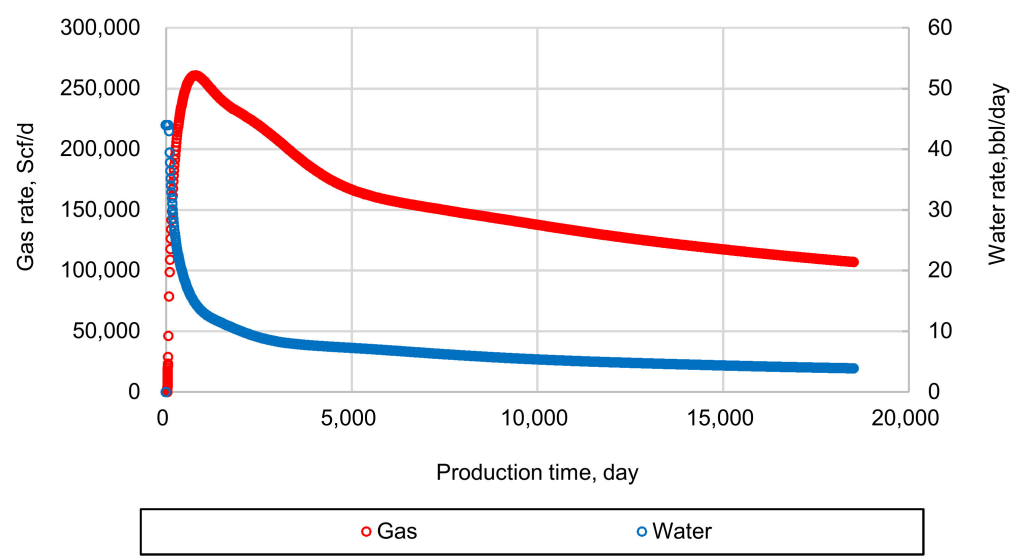

Figure 6. Simulated production rate of a horizontal well in an under-saturated CSG reservoir. 
Following the workflow in Figure 3, the average water saturation can be calculated using the water production history and OWIP, which is calculated using the single-phase (water) FMB method. Note that RNP* is not calculated using average water saturation in the corresponding flow regime; hence, slopes of early radial and formation linear flow regimes on the diagnostic plot are not exactly equal to 0 and 0.5 , respectively. However, flow regimes can still be identified using their distinguishing slopes, as shown in Figure 7a.

(a)

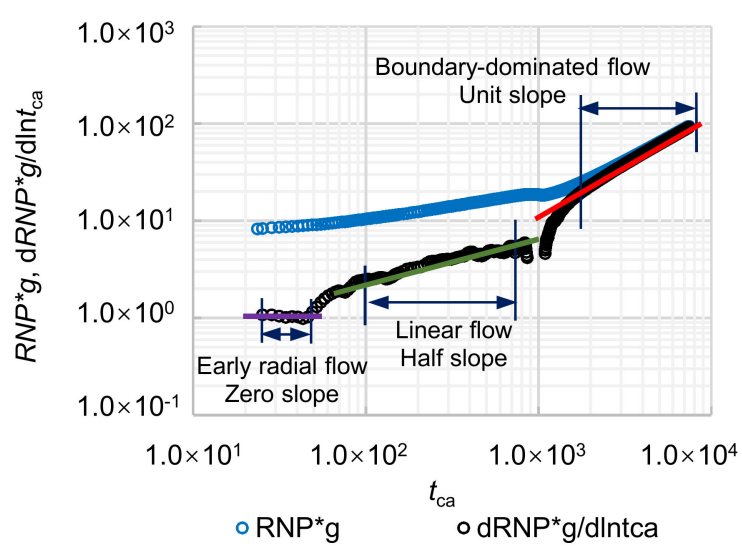

(c) Transient formation linear flow regime

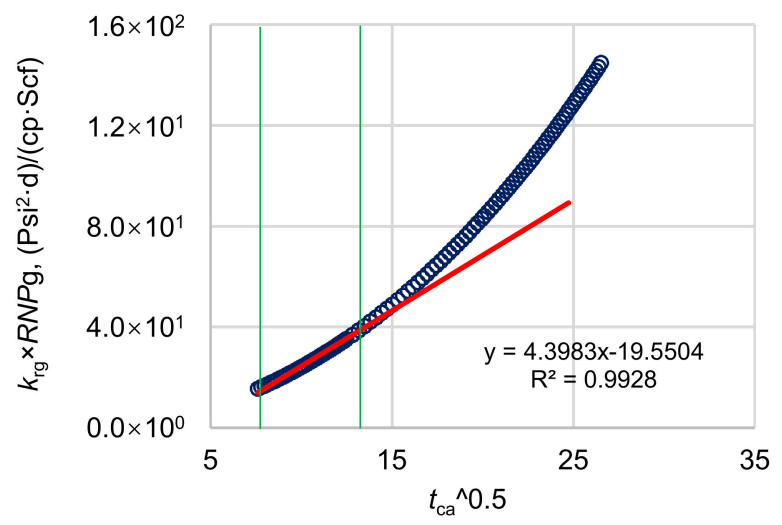

(b)

Early radial flow regime

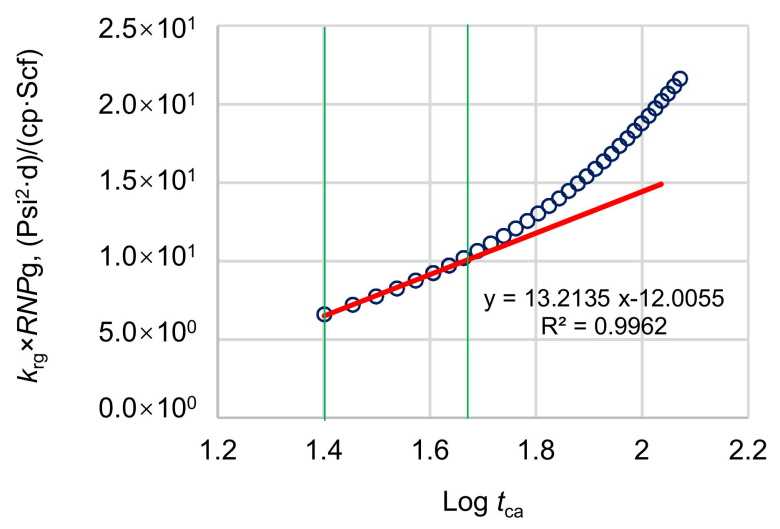

(d)

Boundary-dominated flow regime

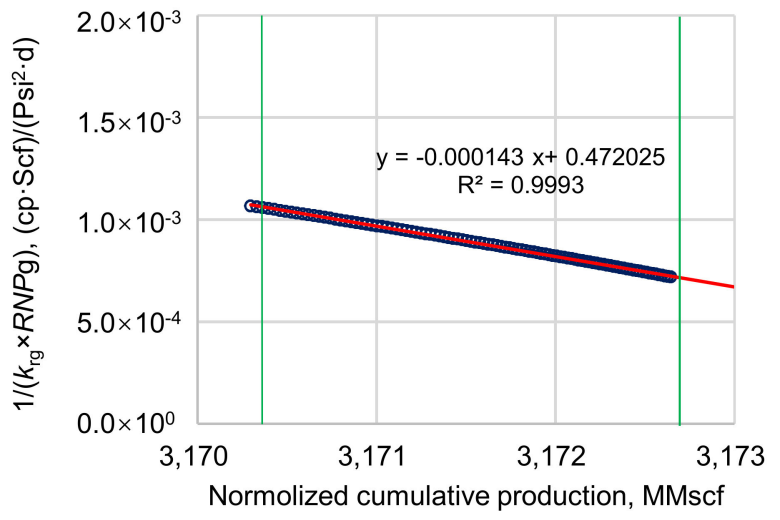

Figure 7. The two phase RTA of the simulated horizontal well in an under-saturated coal seam gas reservoir including (a) diagnostic plot, (b) early radial flow regime, (c) transient formation linear flow regime, and (d) boundary-dominated flow regime.

Following the recognition of the flow regimes in Figure 7a, the production data in each regime is selected to calculate the average water saturation in the AI, and the straight-line technique is employed to extract reservoir properties using the plot of $k_{\mathrm{rg}} \times \mathrm{RNP}_{\mathrm{g}}$ versus $t_{\mathrm{ca}}$. For the simulation case, production data does not change rapidly, and the material balance pseudo-time $\left(t_{\mathrm{ca}}\right)$ can be used instead of superposition time. In the early radial flow regime, the average water saturation is obtained using Equation (5).

Due to the good data quality of simulated water and gas rates, the geometric-average permeability of coal is also extracted using gas production data (Figure $7 \mathrm{~b}$ ). In the transient formation linear flow regime, average water saturation and average pressure are calculated using our presented method, as described in the workflow (Figure 3). Then both horizontal permeability and OGIP are calculated using the straight-line slopes in the transient formation linear flow regime (Figure 7c). In the boundary-dominated flow regime, the average water saturation and average pressure can be obtained using common material balance equations, and the OGIP is extracted from the slope and the y-intercept of the straight-line 
in Figure $7 \mathrm{~d}$. The results for geometric average permeability, horizontal permeability, and OGIP obtained from different flow regimes, and the relative errors, are listed in Table 4.

Table 4. Extracted properties * and relative errors of simulation examples using two phase (water + gas) RTA.

\begin{tabular}{|c|c|c|c|c|}
\hline \multirow[b]{2}{*}{ Calculated Value } & \multicolumn{4}{|c|}{ Flow Regime } \\
\hline & $\begin{array}{c}\text { Early Radial } \\
\text { Flow }\end{array}$ & & near & $\begin{array}{l}\text { Boundary- } \\
\text { Dominated }\end{array}$ \\
\hline Extracted properties & $k_{\mathrm{y}} k_{\mathrm{z}}=2.01$ & $k_{\mathrm{y}}=2.02$ & $O G I P=3536.15$ & $O G I P=3300.87$ \\
\hline Actual properties & $k_{\mathrm{y}} k_{\mathrm{z}}=2.00$ & $k_{\mathrm{y}}=2.00$ & $O G I P=3316.57$ & $O G I P=3316.57$ \\
\hline Relative error & $0.50 \%$ & $1.00 \%$ & $6.62 \%$ & $0.47 \%$ \\
\hline
\end{tabular}

* Note that the units of permeability and OGIP are $\mathrm{mD}$ and MMScf, respectively.

Table 4 indicates that the horizontal coal permeability $\left(k_{\mathrm{y}}\right)$ is obtained with errors lower than $5.0 \%$ using the approach proposed in this study. The geometric-average permeability, calculated in the early radial flow regime, is in good agreement with the input values. In addition, the results also suggest that the OGIP calculated from the boundary-dominated flow regime is more reliable than the that extracted from the transient linear flow regime.

Note that the calculated reservoir properties are in good agreement with the actual parameters, indicating that the proposed method for determination of average water saturation in the AI is a practical approach. In the simulation case study, we do not perform a crosscheck because the properties obtained from the simulation case show good consistency. However, the crosscheck is still an important step for the field case. In the next section, the proposed approach is employed to extract the reservoir properties of a field example located in the Qinshui Basin, China.

\subsection{Field Example}

The field case is based on a horizontal well in the Panzhuang production block, for which the geological and production information are introduced in Section 2 . The horizontal well specification and reservoir parameters that we collected are listed in Table 5. The gas and water production history for a period of 30 months, in addition to the bottomhole flowing pressure data, are shown in Figure 8. As mentioned in the simulation example, because the main fluid is gas in the two phase flow stage, the pressure gradient of the gas along the wellbore is always very small when the production rate is no more than 2.5 MMScf. Hence, we can still assume that the fluid pressure along the horizontal interval is constant in the field case.

Table 5. Reservoir properties * for the target well in the Qinshui Basin, China.

\begin{tabular}{|c|c|}
\hline Parameter & Value \\
\hline Length of horizontal interval, $\mathrm{ft}$ & 8960 \\
\hline Thickness of coal, $\mathrm{ft}$ & 22.38 \\
\hline Cleat porosity, $\%$ & 0.43 \\
\hline Cleat permeability, $\mathrm{mD}$ & 2.47 \\
\hline Coal density, $\mathrm{g} / \mathrm{cm}^{3}$ & 1.50 \\
\hline Gas content, scf/ton & 459.03 \\
\hline Initial pressure, psi & 610.16 \\
\hline Temperature, ${ }^{\circ} \mathrm{F}$ & 94 \\
\hline Langmuir pressure, psi & 362.60 \\
\hline Langmuir volume, Scf/ton & 1362.751 \\
\hline Cleat compressibility, $\mathrm{Psi}^{-1}$ & 0.0001 \\
\hline Water compressibility, $\mathrm{Psi}^{-1}$ & $3.2 \times 10^{-6}$ \\
\hline Initial gas viscosity, $\mathrm{cp}$ & 0.0153 \\
\hline Well radius, $\mathrm{ft}$ & 0.1968 \\
\hline Skin, dimensionless & 0 \\
\hline
\end{tabular}

\footnotetext{
* Taken from the well completion report and core analysis.
} 


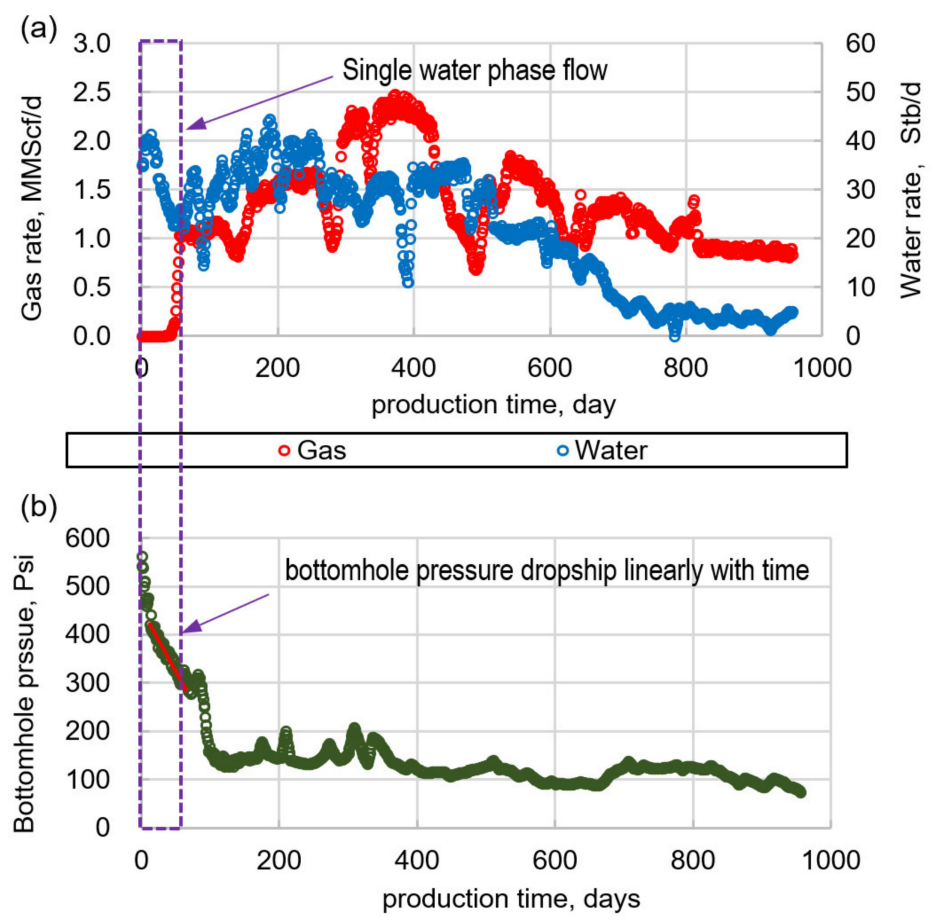

Figure 8. The gas and water production history of the field case: (a) water and gas production rate and (b) bottom-hole flowing pressure.

As shown in Figure 8, initially, water production is relatively constant at $40 \mathrm{Stb} / \mathrm{d}$ for a short period and declines thereafter. The bottom-hole pressure follows a straight line in the early production stage, indicating that the boundary effect dominated the single-phase water production.

For the relative location of the horizontal well in a rectangle area, our targeted well is very close to the shape of model 2 . The approach proposed in this paper is utilized to extract the drainage area and horizontal permeability. Figure 9 shows the single-phase (water) FMB plots, including the diagnostic plot and the straight-line plot for the single-phase (water) FMB of the field example. The reservoir and wellbore properties are listed in Table 5. Note that both Clarkson and Joshi productivity equations are used in our FMB technique for the field example for the purpose of comparison. The comparison can assist in the later crosschecking. The extracted permeabilities using both equations are listed in Table 6 .

(a)

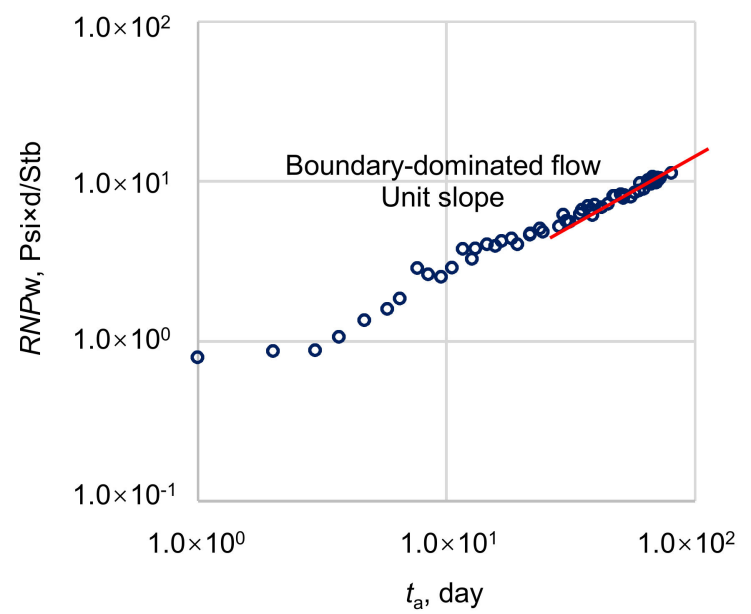

(b)

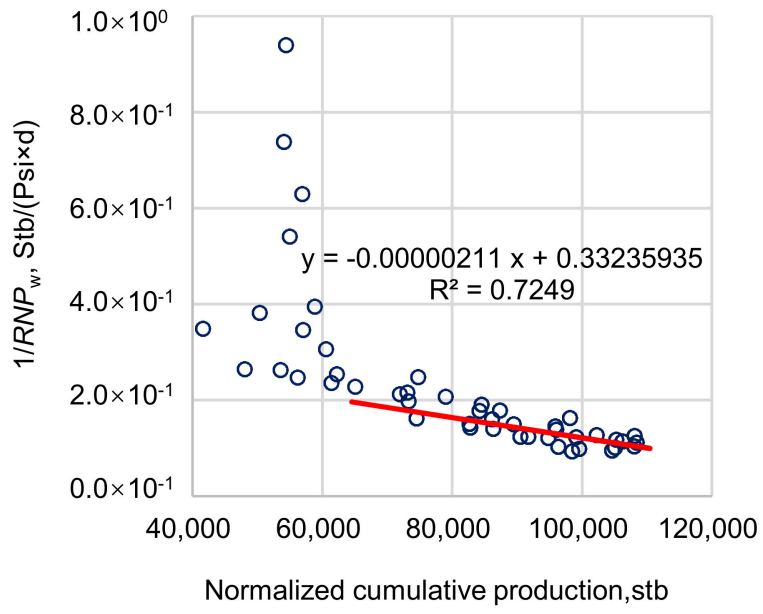

Figure 9. The single-phase (water) FMB of the field case: (a) the diagnostic plot of single-phase (water) and (b) the straight line. 
Table 6. Extracted properties of the field example.

\begin{tabular}{cccc}
\hline \multirow{2}{*}{ Calculated Value } & Single-Phase (Water) FMB & \multicolumn{2}{c}{ Two phase (Water + Gas) RTA } \\
\cline { 2 - 4 } & $\begin{array}{c}\text { Boundary-Dominated } \\
\text { Flow }\end{array}$ & Early Radial Flow & Linear Flow \\
\hline \multirow{3}{*}{ Extracted properties } & $\begin{array}{c}\text { OWIP }=157,516 \mathrm{stb}, A_{\mathrm{dra}}= \\
211.34 \text { acres, } y_{\mathrm{d}}=156 \mathrm{~m}, k_{\mathrm{yJ}} \\
=2.892 \mathrm{mD}, k_{\mathrm{yC}}=2.406 \mathrm{mD}\end{array}$ & $\begin{array}{c}k_{\mathrm{y}} k_{\mathrm{zs}}=0.159 \\
k_{\mathrm{z}}=0.061 \mathrm{mD}\end{array}$ & $k_{\mathrm{y}}=2.572 \mathrm{mD}$ \\
\hline
\end{tabular}

${ }^{*} k_{\mathrm{z}}$ is calculated using average value of $k_{\mathrm{yJ}}, k_{\mathrm{yC}}$ and $k_{\mathrm{y}}$.

After the FMB study in our workflow, the analysis of two phase RTA starts with the correction of the RNP using the appropriate water saturation. To identity the flow regimes, average water saturation calculated using the whole drainage area (obtained by the single-phase FMB) is utilized to identify the early radial flow and formation linear flow regimes on the diagnostic plot (Figure 10a). Note that we cannot use the water saturation in the AI for the diagnostic plots because the flow regimes are not yet identified. Hence, the slopes of each flow regime are not exactly equal to the standard values, which are unit slope for boundary-dominated flow, half slope for formation linear flow, and zero slope for early radial flow. Nonetheless, the slope of each flow regime can still be identified due to its sequence and unique characteristics.

(a)

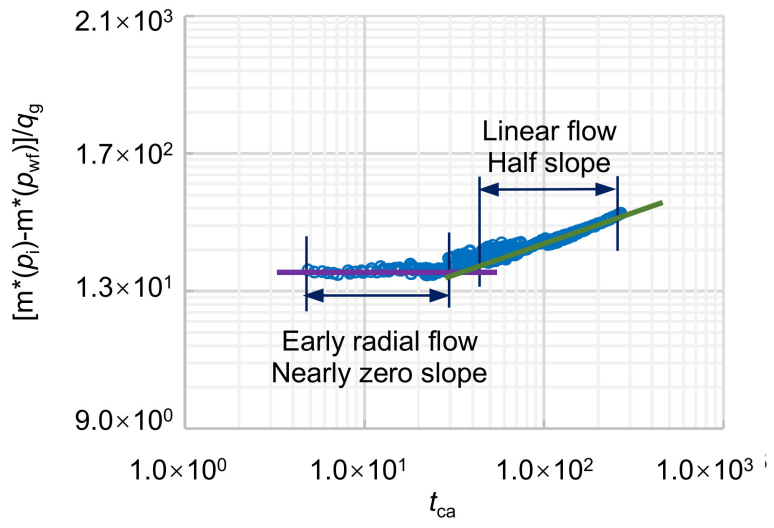

(c)

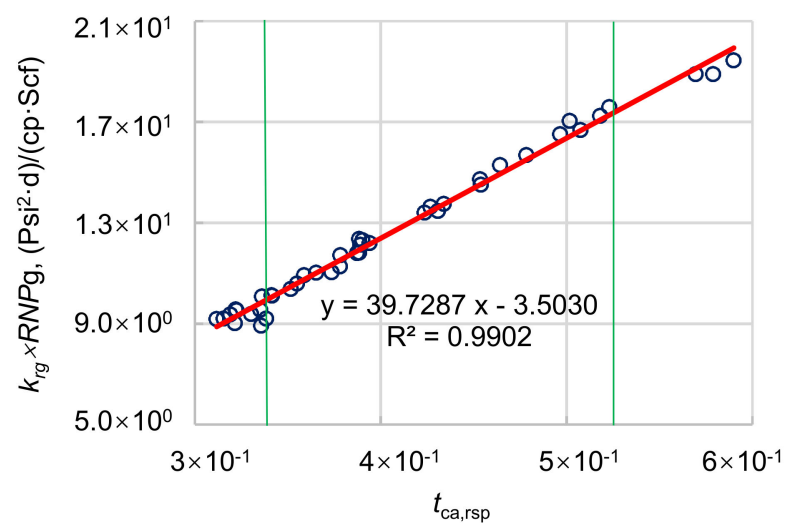

(b) Diagnostic plot (derivative)

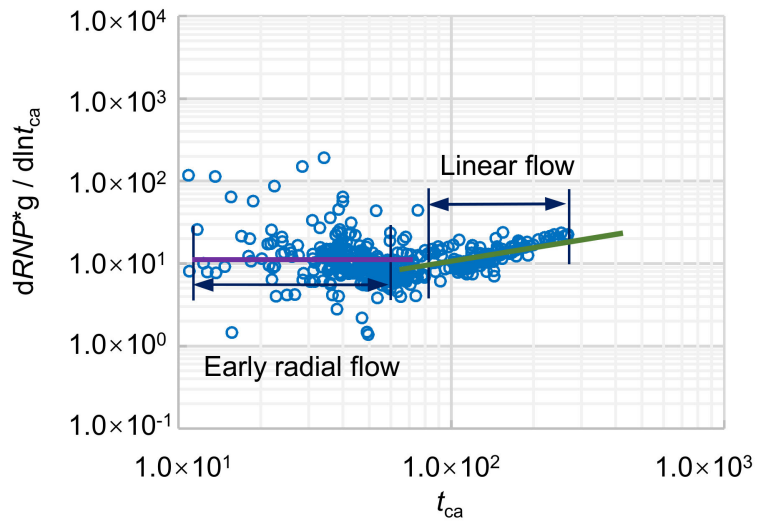

(d) Transient formation linear flow regime

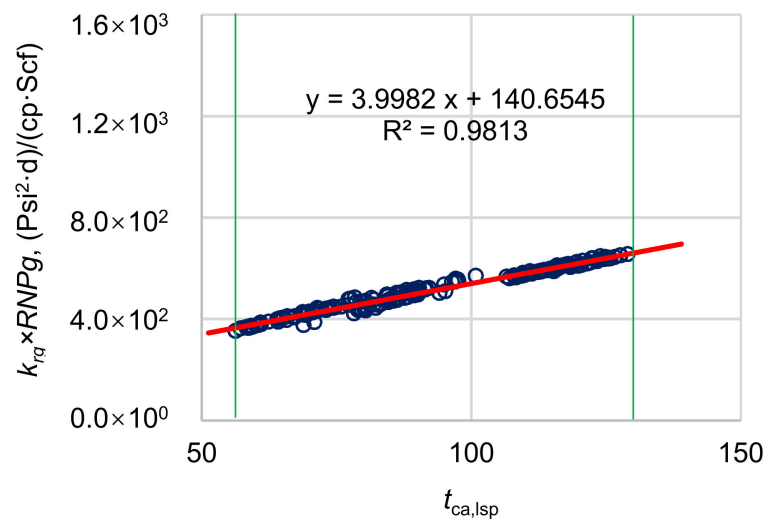

Figure 10. The use of two phase RTA techniques for analyzing flow regimes associated with a horizontal well in the field example: (a) diagnostic curve (RNP*), (b) diagnostic curve (derivative), (c) early radial flow of gas phase, and (d) formation linear flow. 
After the flow regimes are identified in Figure 10a, average water saturation values in the AI can be precisely calculated in both early radial flow and transient formation linear flow regimes. Finally, reservoir properties can be later estimated using the presented methods to correct RNP and extract reservoir properties.

Figure 10a,b shows the diagnostic plot and its derivative for two phase RTA for the field example. Due to the long horizontal interval $(8960 \mathrm{ft})$ and short production time $(2.5$ year), only early radial flow and transient formation linear flow regimes are identified. For early radial flow and transient linear flow regimes of the field example, the water saturation in the AI is obtained using Equations (5) and (9), respectively. Due to the fluctuation of the gas production rate, the superposition time $\left(t_{\mathrm{ca}, \mathrm{lsp}}\right)$ is employed for the field case. The geometric-average permeability is obtained using the water saturation in the AI in the early radial flow regime (Figure 10c).

Because the boundary effects have not yet dominated the flow, only the horizontal permeability of coal $\left(k_{\mathrm{y}}\right)$ can be extracted using the straight-line slope when $k_{\mathrm{rg}} \times \mathrm{RNP}_{\mathrm{g}}$ is plotted versus superposition time $\left(t_{\mathrm{ca}, \text { lsp }}\right)$ in the transient linear flow regime (Figure 10d). In each flow regime, the slopes of the straight lines are employed to extract the reservoir permeabilities and the OGIP using our proposed two phase RTA technique. The results obtained from the slopes from Figure $10 \mathrm{~b}-\mathrm{d}$ can be seen in Table 6.

In Table 6, reservoir information obtained using both the proposed single-phase (water) FMB and two phase (water + gas) RTA methods can be crosschecked. The proposed single-phase FMB method is applied to extract the OWIP, the drainage area of the horizontal well, the investigation distance (based on the rectangle shape of the drainage area), and horizontal permeability. Because the relative position of the horizontal well in the drainage area is close to that of model 2, the permeability values obtained using the Joshi and Clarkson equations are similar in Table 6, and are also similar to the results from the two phase RTA study. This crosscheck ensures the consistency between the FMB and the two phase RTA. For the two phase RTA study, because the boundary-dominated flow regime is not observed, $k_{\mathrm{y}}$ and $k_{\mathrm{z}}$ are calculated in the early radial flow and transient linear flow regimes. The vertical permeability of coal $\left(k_{\mathrm{z}}\right)$ is extracted to be $0.061 \mathrm{mD}$ when $k_{\mathrm{y}}=2.623$ $\mathrm{mD}$ (calculated using the average value of $k_{\mathrm{yJ}}, k_{\mathrm{yC}}$, and $k_{\mathrm{y}}$ ).

The extracted $k_{\mathrm{y}}$ is the average permeability of the coal seam along the horizontal interval $(8960 \mathrm{ft})$. The coal permeability extracted by the proposed single-phase (water) FMB and two phase RTA are in good agreement with the coal permeability measured by the core analysis. The integrated analysis of early radial and formation linear flow regimes provides a realistic estimation of coal permeability along the horizontal interval.

\section{Conclusions}

In this study, a workflow is presented including the single-phase (water) FMB method and two phase RTA, using the concept of the AI, to analyze gas and water production data in horizontal CSG wells and extract reservoir properties. Simulation cases and a field case are presented to validate the proposed workflow and the application of the improved techniques. The conclusions can be drawn as follows:

(1) The permeability extracted from the single-phase FMB method requires an appropriate productivity equation. The flow regime prior to boundary-dominated flow determines the type of production equation. The Joshi equation is suitable for the situation in which elliptical flow obviously occurs before boundary-dominated flow, and the Clarkson equation works well for the situation in which formation linear flow exists prior to boundary-dominated flow.

(2) The average water saturation of the drainage area is obtained using the OWIP from single-phase (water) FMB. The accuracy of this water saturation is sufficient to identify the flow regimes from a diagnostic plot in the two phase RTA technique. However, the water saturation in the AI is necessary for the extraction of properties in each flow regime. 
(3) A workflow application to a field example from the Qinshui Basin indicates that the proposed single-phase (water) FMB and two phase RTA methods can be utilized simultaneously to improve the accuracy of properties' extraction from the production history. The proposed workflow in this study can extract the reservoir permeabilities and OGIP with acceptable accuracy.

Author Contributions: Conceptualization, A.S.; Formal analysis, S.Z. and A.S.; Methodology, S.Z. and A.S.; Visualization, S.Z.; Writing-review \& editing, S.Z. and A.S. Both authors have read and agreed to the published version of the manuscript.

Funding: China Major Science and Technique Project (2016ZX05066004-001); China Post-doctorate funding (2019M663564).

Institutional Review Board Statement: Not applicable.

Informed Consent Statement: Not applicable.

Data Availability Statement: The study did not report any data.

Acknowledgments: This paper was financially supported by China Major Science and Technique Project (2016ZX05066004-001), which is acknowledged. In addition, this research was also supported by China Post-doctorate funding (2019M663564). We would also like to thank the editor and anonymous reviewers for their constructive comments.

Conflicts of Interest: The authors declare no conflict of interest.

\section{Nomenclature}

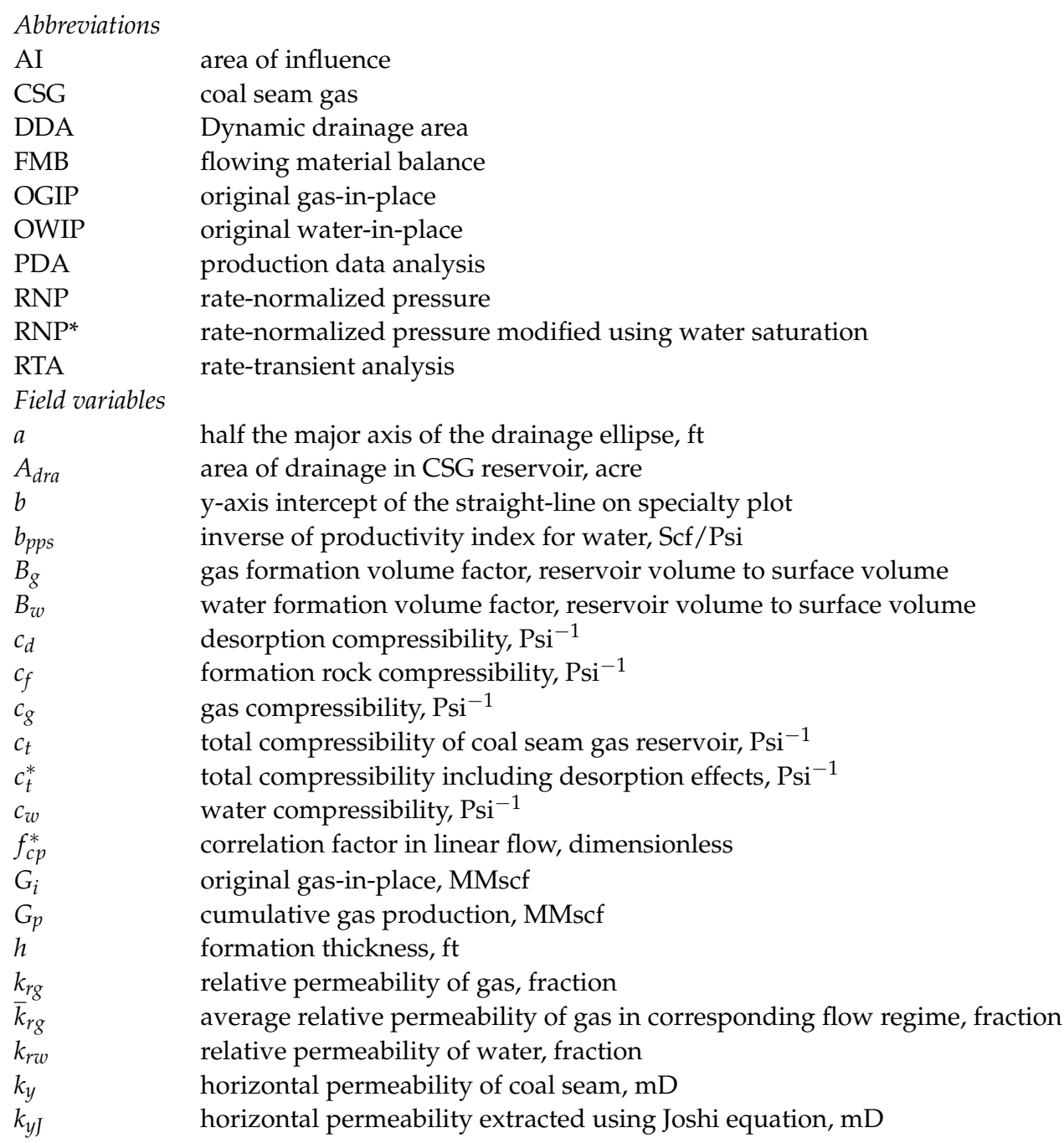




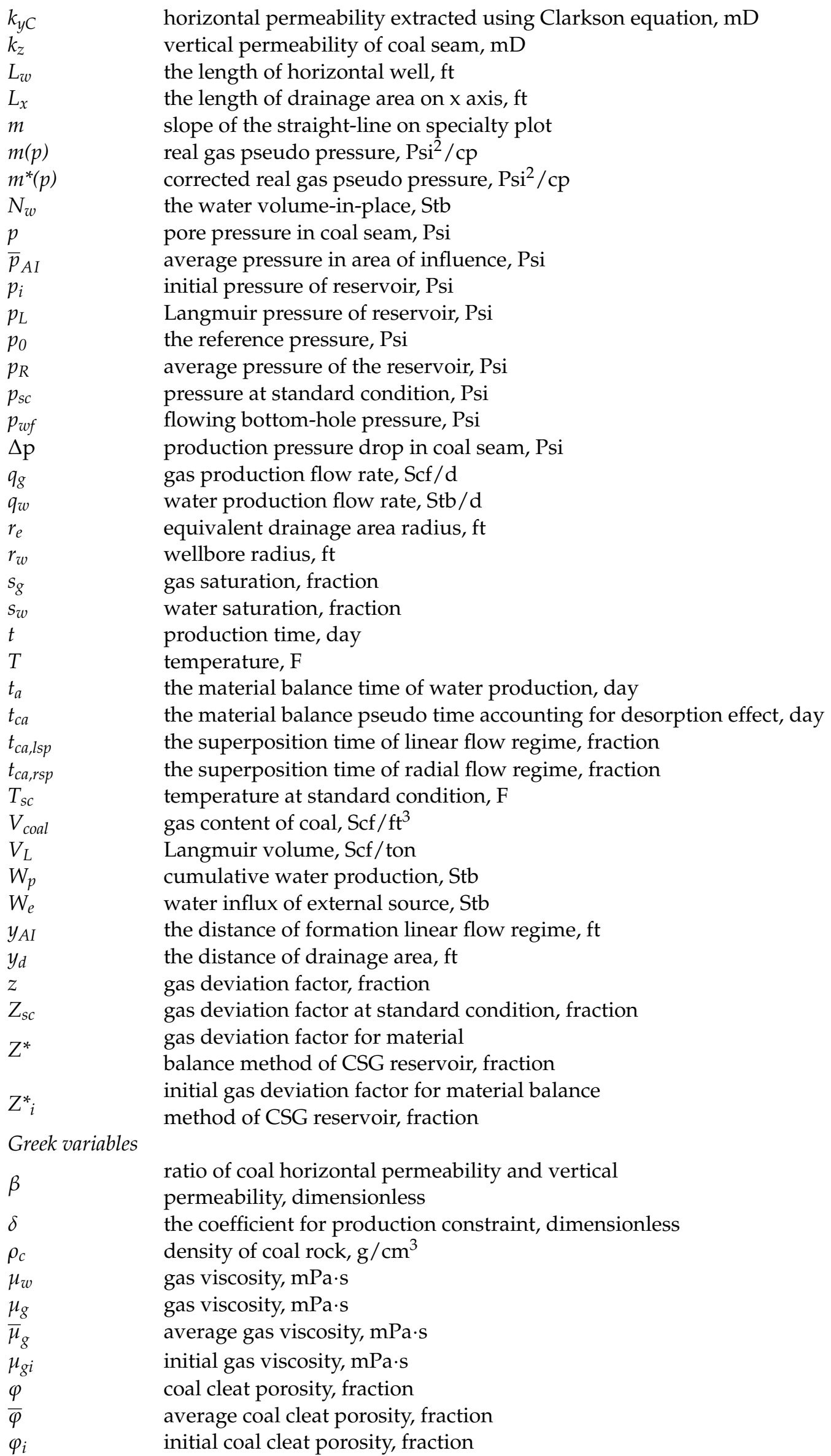




\section{Appendix A. Single-Phase (Water) FMB Equations for a Horizontal Well}

During the early production period (single-phase water flow), when the water rate is constant, the $R N P_{w}$ (rate-normalized pressure for water production) can be expressed by:

$$
R N P_{w}=\frac{p_{i}-p_{w f}}{q_{w}}
$$

When the boundary-dominated flow regime is observed, coal permeability and OWIP can be derived using the FMB technique developed for a horizontal well. A unit slope straight line on the diagnostic plot (the plot of $R N P_{w}$ versus $t_{a}$ ) indicatesS that boundary effects have dominated the water flow. $t_{a}$ is the material balance time for water production and is expressed by:

$$
t_{a}=\frac{N_{w}}{W_{p} B_{w}}
$$

The derivation of the FMB for a horizontal well begins with the water compressibility equation, where the difference between initial reservoir pressure and average reservoir pressure can be calculated by Equation (A3):

$$
p_{i}-p_{R}=\frac{W_{p} B_{w}}{N_{w} c_{t}}
$$

Having the water productivity equation, the difference between average reservoir pressure and bottom-hole pressure can be calculated by Equation (A4):

$$
p_{R}-p_{w f}=q_{w} \times b_{p s s}, q_{w}=\frac{p_{R}-p_{w f}}{b_{p s s}}
$$

Adding Equation (A3) to Equation (A4) and rearranging the result in the general form of the FMB equation for water yields:

$$
\frac{q_{w}}{\Delta p}=-\frac{W_{p} B_{w}}{\Delta p c_{t}} \frac{1}{N_{w} b_{p s s}}+\frac{1}{b_{p s s}}
$$

In Equation (A5), $b_{p s s}$ accounts for the pressure loss due to the pseudo-steady state inflow of fluid (Equation (A4)). Equation (A5) can be linearized to extract coal permeability and OWIP when the productivity equation is known and results in:

$$
\left\{\begin{array}{c}
\frac{q_{w}}{\Delta p}=-m x+\frac{1}{b_{p s s}} \\
x=\frac{W_{p} B_{w}}{\Delta p c_{t}}, m=-\frac{1}{N_{w} b_{p s s}}
\end{array}\right.
$$

Equation (A6) indicates that there is a linear relationship between the pressurenormalized rate and the normalized cumulative production in the boundary-dominated flow regime. The slope and intercept of the straight line can be utilized to calculate the OWIP $\left(N_{w}\right)$. When porosity and thickness are known, the drainage area of the horizontal well can be calculated. The average permeability of the coal seam can be extracted using the intercept $\left(1 / b_{p s s}\right)$, which requires the choice of an appropriate productivity equation.

Because the rate of pressure decline at the flow boundary is small for a horizontal well, the productivity equations of steady state flow may be selected to extract the permeability. Depending on the relative position of the horizontal well in the drainage area, elliptical or formation linear flow regimes may occur, followed by the boundary-dominated flow regime. 
The productivity of a horizontal well can be described using the Joshi equation [46] for an elliptical drainage area, or the Clarkson equation [28] for formation linear flow, which are shown as below:

$$
\begin{gathered}
q_{w}=\frac{k_{y} h\left(p_{R}-p_{w f}\right) /\left(\mu_{w} B_{w}\right)}{141.2\left[\ln \frac{a+\sqrt{a^{2}-\left(L_{w} / 2\right)^{2}}}{L_{w} / 2}+\beta^{2} \frac{h}{L_{w}} \ln \frac{h}{2 r_{w}}\right]} \\
q_{w}=\frac{k_{h} h\left(p_{R}-p_{w f}\right) /\left(\mu_{w} B_{w}\right)}{141.2\left(\frac{4 y_{d}}{\pi L_{w}}\right)}
\end{gathered}
$$

where $(a)$ is the half major axis of the drainage ellipse and the drainage distance $\left(y_{\mathrm{d}}\right)$ can be estimated using the following equations:

$$
\left\{\begin{array}{c}
y_{d}=\frac{O W I P}{\varphi h L_{w}}, r_{e}=\sqrt{\frac{O W I P}{\varphi h \pi}} \\
a=\left(L_{w} / 2\right)\left[\frac{1}{2}+\sqrt{\frac{1}{4}+\frac{1}{\left(L_{w} / 2 r_{e}\right)^{4}}}\right]^{0.5}
\end{array}\right.
$$

Generally, horizontal permeability of the coal seam is greater than the vertical permeability, and the horizontal drainage area is also much larger than the vertical drainage area. Hence, the contribution of vertical flow is negligible in the boundary-dominated flow regime in under-saturated CSG reservoirs, and $b_{p s s}$ using both productivity equations can be written as:

$$
\begin{gathered}
b_{p s s}=\frac{141.2\left(\mu_{w} B_{w}\right)\left[\ln \frac{a+\sqrt{a^{2}-\left(L_{w} / 2\right)^{2}}}{L_{w} / 2}\right]}{k_{y} h} \\
b_{p s s}=\frac{141.2\left(\mu_{w} B_{w}\right)\left(\frac{2 \pi y_{d}}{L_{w}}\right)}{k_{y} h}
\end{gathered}
$$

Finally, the horizontal permeability of the coal can be extracted using Equations (A10) and/or (A11).

Table A1. Conversion Table.

\begin{tabular}{ccc}
\hline Quantity & Field Unit & SI Unit \\
\hline Pressure & $1 \mathrm{psi}$ & $6894.76 \mathrm{~Pa}$ \\
\hline Length & $1 \mathrm{ft}$. & $0.3048 \mathrm{~m}$ \\
\hline \multirow{2}{*}{ Volume } & $1 \mathrm{stb}$ & $0.159 \mathrm{~m}^{3}$ \\
\cline { 2 - 3 } & $1 \mathrm{sft}^{3}$ or 1 Scf & $0.0283 \mathrm{~m}^{3}$ \\
\hline
\end{tabular}

\section{Appendix B. Two Phase RTA Equations of CSG Reservoirs}

In under-saturated CSG reservoirs, pseudo-pressure, $m^{*}(p)$, and material balance pseudo-time $\left(t_{\mathrm{ca}}\right)$ are used to account for relative permeability, gas-property variation, and desorption effect with pore pressure $[9,12] . m^{*}(p)$ and $t_{\mathrm{ca}}$ can be obtained using Equations (A12) and (A13), respectively.

$$
\begin{gathered}
m^{*}(p)=2 \int_{p_{0}}^{p} \frac{k_{r g} p}{\mu_{g} z} d p \\
t_{c a}=\frac{\left(c_{t}^{*} \mu_{g}\right)_{i}}{q_{g}} \int_{0}^{t} \frac{q_{g}}{\overline{c_{t}^{*} \mu_{g}}} d t
\end{gathered}
$$


This integral process needs to seek the relationship between average water saturation and average reservoir pressure [5]. The total compressibility $\left(c_{t}^{*}\right)$ in $t_{\mathrm{ca}}$ includes the effect of desorption on gas compressibility, shown by Equation (A14). The desorption compressibility $\left(c_{d}\right)$ is calculated using Equation (A15).

$$
\begin{gathered}
c_{t}^{*}=s_{w} c_{w}+c_{f}+c_{d}+s_{g} c_{g} \\
c_{d}=\frac{B_{g} \rho_{c} V_{L} p_{L}}{32.04\left(p_{R}+p_{L}\right)^{2} \varphi}
\end{gathered}
$$

For two phase RTA, the RNP* can be used for a diagnostic plot to identify flow regimes. Once the flow regimes are identified, straight-line methods are used to extract reservoir properties. In the application of the straight-line technique, single-phase RNP is modified using the gas relative permeability values. Two forms of RNP for two phase RTA in under-saturated CSG reservoirs can be expressed by the following equations:

$$
\begin{gathered}
R N P_{g}^{*}=\frac{m^{*}\left(p_{i}\right)-m^{*}\left(p_{w f}\right)}{q_{g}} \\
\bar{k}_{r g} \times R N P_{g}=\frac{\bar{k}_{r g}\left[m\left(p_{i}\right)-m\left(p_{w f}\right)\right]}{q_{g}}
\end{gathered}
$$

For a horizontal well that penetrates most part of the drainage area, the pressure decline in the transient formation linear flow regime can dramatically influence the fluid properties. Hence, the correction factor $\left(f_{c p}^{*}\right)$ must account for the change in gas properties [14,45], which can be written as:

$$
f_{c p}^{*}=\sqrt{\frac{\left(\mu_{g} c_{t}^{*}\right)_{i}}{\overline{\mu_{g} c_{t}^{*}}}}
$$

Commonly, in transient flow regimes, neither the production rate nor the bottom-hole pressure can be maintained at constant levels. The flow regime can be identified using material balance pseudo-time $\left(t_{\mathrm{ca}}\right)$, but property extraction using straight-line techniques requires the superposition time. The superposition time for early radial flow and transient linear flow regimes can be expressed as:

$$
\begin{gathered}
t_{c a, r s p}=\sum_{i=1}^{n} \frac{\left(q_{g i}-q_{g i-1}\right)}{q_{g n}} \log \left[\left(t_{c a}\right)_{i}-\left(t_{c a}\right)_{i-1}\right] \\
t_{c a, l s p}=\sum_{i=1}^{n} \frac{\left(q_{g i}-q_{g i-1}\right)}{q_{g n}} \sqrt{\left(t_{c a}\right)_{i}-\left(t_{c a}\right)_{i-1}}
\end{gathered}
$$

For the boundary-dominated flow regime, the average pressure and water saturation are needed when the two phase flowing material balance method is applied. Seidle's MBE [10] is widely used to calculate both average reservoir pressure and average water saturation [5,29], expressed using Equations (A21)-(A23). An iterative calculation process is needed to obtain average pressure and average water saturation during boundarydominated flow.

$$
Z^{*}=\frac{\frac{p}{Z^{*}}=\frac{p_{i}}{Z_{i}^{*}}\left(1-\frac{G_{p}}{G_{i}}\right)}{\frac{\rho_{c} V_{L} p_{s c}}{32.037 \varphi_{i} Z_{s c} T_{s c}\left(p+p_{L}\right)}+\left(1-s_{w}\right) \exp \left[-c_{f}\left(p_{i}-p\right)\right]}
$$




$$
s_{w}=\frac{s_{w i}\left[1+c_{w}\left(p_{i}-p\right)\right]+\frac{B_{w v}\left(W_{e}-W_{p}\right)}{7758.4 A_{d r a} h \varphi_{i}}}{\exp \left[c_{f}\left(p_{i}-p\right)\right]}
$$

For the two phase (water + gas) RTA, the straight-line techniques and parameter extraction equations derived for tight and shale gas reservoirs can still be used to calculate the reservoir and stimulation parameters in under-saturated CSG reservoirs. An early radial flow regime that exists for a short production period may not be captured by early production data. If early radial flow can be identified, the geometric-average permeability $\sqrt{k_{y} k_{z}}$ can be extracted. $k_{\mathrm{y}}$ is the coal permeability perpendicular to the horizontal interval and $k_{\mathrm{z}}$ is the vertical permeability of the coal seam. The horizontal permeability $\left(k_{\mathrm{y}}\right)$ can be extracted from the transient linear flow and the OGIP can be estimated by the end time of the formation linear flow regime using the end time of linear flow $\left(t_{\text {ehs }}\right)$ and the equation listed in Table 1.

\section{References}

1. Clarkson, C. Production data analysis of unconventional gas wells: Review of theory and best practices. Int. J. Coal Geol. 2013, 109-110, 101-146. [CrossRef]

2. Clarkson, C.R.; Behmanesh, H.; Chorney, L. Production-data and pressure-transient analysis of horseshoe canyon coalbedmethane wells-Part II: Accounting for dynamic skin. J. Can. Pet. Technol. 2013, 52, 41-53. [CrossRef]

3. Clarkson, C.R.; Beierle, J. Integration of microseismic and other post-fracture surveillance with production analysis: A tight gas study. J. Nat. Gas Sci. Eng. 2011, 3, 382-401. [CrossRef]

4. Clarkson, C.R.; Jordan, C.L.; Ilk, D.; Blasingame, T.A. Rate-transient analysis of 2-phase (gas + water) CBM wells. J. Nat. Gas Sci. Eng. 2012, 8, 106-120. [CrossRef]

5. Clarkson, C.; Salmachi, A. Rate-transient analysis of an undersaturated CBM reservoir in Australia: Accounting for effective permeability changes above and below desorption pressure. J. Nat. Gas Sci. Eng. 2017, 40, 51-60. [CrossRef]

6. Clarkson, C.R.; Bustin, M. Coalbed methane: Current field-based evaluation methods. SPE Reserv. Eval. Eng. 2011, 14, 60-75. [CrossRef]

7. Clarkson, C.R.; McGovern, J. Optimization of coalbed methane reservoir exploration and development strategies through integration of simulation and economics. SPE Reserv. Eval. Eng. 2005, 8, 502-519. [CrossRef]

8. Clarkson, C.R. Case study: Production data and pressure transient analysis of horseshoe canyon CBM wells. J. Can. Pet. Technol. 2008. [CrossRef]

9. Clarkson, C.R.; Bustin, R.M.; Seidle, J.P. Production-data analysis of single-phase (gas) coalbed-methane wells. SPE Reserv. Eval. Eng. 2007, 10, 312-331. [CrossRef]

10. Seidle, J. Fundamentals of Coalbed Methane Reservoir Engineering; PennWell Books: Tulsa, OK, USA, 2011.

11. Clarkson, C.R. Case Study: Production Data and Pressure Transient Analysis of Horseshoe Canyon CBM Wells. J. Can. Pet. Technol. 2009, 48, 27-53. [CrossRef]

12. Clarkson, C.R.; Jordan, C.L.; Gierhart, R.R.; Seidle, J.P. Production data analysis of coalbed-methane wells. SPE Reserv. Eval. Eng. 2008, 11, 311-325. [CrossRef]

13. Tian, Q.; Cui, Y.; Luo, W.; Liu, P.; Ning, B. Transient Flow of a horizontal well with multiple fracture wings in coalbed methane reservoirs. Energies 2020, 13, 1498. [CrossRef]

14. Qanbari, F.; Clarkson, C. Rate-transient analysis of liquid-rich tight/shale reservoirs using the dynamic drainage area concept: Examples from North American reservoirs. J. Nat. Gas Sci. Eng. 2016, 35, 224-236. [CrossRef]

15. Ibrahim, M.H.; Wattenbarger, R.A. Analysis of rate dependence in transient linear flow in tight gas wells. In Proceedings of the Abu Dhabi International Petroleum Exhibition and Conference, Abu Dhabi, United Arab Emirates, 5-8 November 2006; Society of Petroleum Engineers: Abu Dhabi, United Arab Emirates, 2006.

16. Cheng, Y.; Lee, W.J.; McVay, D.A. A new approach for reliable estimation of hydraulic fracture properties in tight gas wells. In Proceedings of the SPE Hydraulic Fracturing Technology Conference SPE-105767-MS, College Station, TX, USA, 29-31 January 2007; Society of Petroleum Engineers: College Station, TX, USA, 2007.

17. Qanbari, F.; Clarkson, C.R. A new method for production data analysis of tight and shale gas reservoirs during transient linear flow period. J. Nat. Gas Sci. Eng. 2013, 14, 55-65. [CrossRef]

18. Ozkan, E.; Brown, M.L.; Raghavan, R.; Kazemi, H. Comparison of fractured-horizontal-well performance in tight sand and shale reservoirs. SPE Reserv. Eval. Eng. 2011, 14, 248-259. [CrossRef]

19. Behmanesh, H.; Hamdi, H.; Clarkson, C.R. Production data analysis of tight gas condensate reservoirs. J. Nat. Gas Sci. Eng. 2015, 22, 22-34. [CrossRef]

20. Clarkson, C.R.; Qanbari, F. Transient flow analysis and partial water relative permeability curve derivation for low permeability undersaturated coalbed methane wells. Int. J. Coal Geol. 2015, 152, 110-124. [CrossRef] 
21. Salmachi, A.; Dunlop, E.; Rajabi, M.; Yarmohammadtooski, Z.; Begg, S. Investigation of permeability change in ultra-deep coal seams using time-lapse pressure transient analysis: A pilot project in the Cooper basin, Australia. AAPG Bull. 2018. [CrossRef]

22. Pan, Z.; Wood, D.A. Coalbed methane (CBM) exploration, reservoir characterisation, production, and modelling: A collection of published research (2009-2015). J. Nat. Gas Sci. Eng. 2015, 26, 1472-1484. [CrossRef]

23. Zhu, S.-Y.; Peng, X.-L.; Du, Z.-M.; Wang, C.-W.; Deng, P.; Mo, F.; Lei, Y.; Wang, M. Modeling of coal fine migration during CBM production in high-rank coal. Transp. Porous Media 2017, 118, 65-83. [CrossRef]

24. Salmachi, A.; Rajabi, M.; Wainman, C.; Mackie, S.; McCabe, P.; Camac, B.; Clarkson, C. History, Geology, In Situ Stress Pattern, Gas Content and Permeability of Coal Seam Gas Basins in Australia: A Review. Energies 2021, 14, 2651. [CrossRef]

25. Zhang, J.; Zhang, B.; Xu, S.; Feng, Q.; Zhang, X.; Elsworth, D.; Sciubba, E. Interpretation of gas/water relative permeability of coal using the hybrid Bayesian-assisted history matching: New insights. Energies 2021, 14, 626. [CrossRef]

26. Yarmohammadtooski, Z.; Salmachi, A.; White, A.; Rajabi, M. Fluid flow characteristics of bandanna coal formation: A case study from the Fairview Field, eastern Australia. Aust. J. Earth Sci. 2017, 64, 319-333. [CrossRef]

27. Ren, J.; Zhang, L.; Ren, S.; Lin, J.; Meng, S.; Ren, G.; Gentzis, T. Multi-branched horizontal wells for coalbed methane production: Field performance and well structure analysis. Int. J. Coal Geol. 2014, 131, 52-64. [CrossRef]

28. Clarkson, C.; Qanbari, F. A semi-analytical method for forecasting wells completed in low permeability, undersaturated CBM reservoirs. J. Nat. Gas Sci. Eng. 2016, 30, 19-27. [CrossRef]

29. Salmachi, A.; Yarmohammadtooski, Z. Production data analysis of coalbed methane wells to estimate the time required to reach to peak of gas production. Int. J. Coal Geol. 2015, 141-142, 33-41. [CrossRef]

30. Mohan, K.; Scott, K.D.; Monson, G.D.; Leonard, P.A. A systematic approach to understanding well performance in unconventional reservoirs: A wolfcamp case study. In Proceedings of the SPE/AAPG/SEG Unconventional Resources Technology Conference, Denver, CO, USA, 12-14 August 2013.

31. Nobakht, M.; Clarkson, C.R. A new analytical method for analyzing linear flow in tight/shale gas reservoirs: Constant-flowingpressure boundary condition. SPE Reserv. Eval. Eng. 2012, 15, 370-384. [CrossRef]

32. Zhu, S.; Salmachi, A.; Du, Z. Two phase rate-transient analysis of a hydraulically fractured coal seam gas well: A case study from the Ordos Basin, China. Int. J. Coal Geol. 2018, 195, 47-60. [CrossRef]

33. Chenglin, L.; Changbo, C.; Mingzhu, F. Coalbed methane resource assessment in China. China Coalbed Methane 2009, 6, 3-6, (In Chinese with English abstract).

34. Yuewu, L.; Zhongliang, S.; Hongbin, F. Review on CBM desorption/adsorption mechanism. Well Test. 2010, 19, 37-44, (In Chinese with English abstract).

35. Lv, Y.; Tang, D.; Xu, H.; Luo, H. Production characteristics and the key factors in high-rank coalbed methane fields: A case study on the Fanzhuang block, southern Qinshui Basin, China. Int. J. Coal Geol. 2012, 96-97, 93-108. [CrossRef]

36. Zou, C. Unconventional Petroleum Geology; Elsevier: Amsterdam, The Netherlands, 2013.

37. Zhao, J.; Tang, D.; Xu, H.; Lv, Y.; Tao, S. High production indexes and the key factors in coalbed methane production: A case in the Hancheng block, southeastern Ordos Basin, China. J. Pet. Sci. Eng. 2015, 130, 55-67. [CrossRef]

38. Zhao, J.; Xu, H.; Tang, D.; Mathews, J.P.; Li, S.; Tao, S. Coal seam porosity and fracture heterogeneity of macrolithotypes in the Hancheng Block, eastern margin, Ordos Basin, China. Int. J. Coal Geol. 2016, 159, 18-29. [CrossRef]

39. Dai, S.; Ren, D.; Chou, C.-L.; Finkelman, R.B.; Seredin, V.V.; Zhou, Y. Geochemistry of trace elements in Chinese coals: A review of abundances, genetic types, impacts on human health, and industrial utilization. Int. J. Coal Geol. 2012, 94, 3-21. [CrossRef]

40. Shao, L.; Xiao, Z.; He, Z.; Liu, Y.; Shang, L.; Zhang, P. Palaeogeography and coal accumulation for coal measures of the carboniferous-Permian in Qinshui Basin, southeastern Shanxi Province. J. Palaeogeogr. 2006, 8, 43-52.

41. Cai, Y.; Liu, D.; Yao, Y.; Li, J.; Qiu, Y. Geological controls on prediction of coalbed methane of no. 3 coal seam in southern Qinshui Basin, North China. Int. J. Coal Geol. 2011, 88, 101-112. [CrossRef]

42. Liu, H.; Sang, S.; Wang, G.; Li, M.; Xu, H.; Liu, S.; Li, J.; Ren, B.; Zhao, Z.; Xie, Y. Block scale investigation on gas content of coalbed methane reservoirs in southern Qinshui basin with statistical model and visual map. J. Pet. Sci. Eng. 2014, 114, 1-14. [CrossRef]

43. Wang, B.; Sun, F.; Tang, D.; Zhao, Y.; Song, Z.; Tao, Y. Hydrological control rule on coalbed methane enrichment and high yield in FZ block of Qinshui Basin. Fuel 2015, 140, 568-577. [CrossRef]

44. Clarkson, C.R.; Qanbari, F. History matching and forecasting tight gas condensate and oil wells by use of an approximate semianalytical model derived from the dynamic-drainage-area concept. SPE Reserv. Eval. Eng. 2016, 19, 540-552. [CrossRef]

45. Qanbari, F.; Clarkson, C.R. Analysis of transient linear flow in tight oil and gas reservoirs with stress-sensitive permeability and multi-phase flow. In Proceedings of the Canadian Unconventional Resources Conference, Calgary, AB, Canada, 5 November 2013.

46. Joshi, S.D. Augmentation of Well Productivity Using Slant and Horizontal Wells. J. Pet. Technol. 1986. [CrossRef] 